\title{
Palladium-Catalyzed C-H Diarylation of Ferrocenecarboxylic Acids with Aryl Iodides
}

\author{
Jia-Chen Xiang ${ }^{\mathrm{a}, \mathrm{b}, \dagger}$, Zhi-Jie Wu $^{\mathrm{a}, \mathrm{c}, \dagger}$, Qing Gu${ }^{*, \mathrm{a}}$ and Shu-Li You ${ }^{*, \mathrm{a}, \mathrm{c}}$
}

\footnotetext{
${ }^{a}$ State Key Laboratory of Organometallic Chemistry, Center for Excellence in Molecular Synthesis, Shanghai Institute of Organic Chemistry, Chinese Academy of Sciences, 345 Lingling Lu, Shanghai 200032, China

${ }^{\mathrm{b}}$ Key Laboratory of Pesticide \& Chemical Biology, Ministry of Education, College of Chemistry, Central China Normal University, Wuhan 430079, China

${ }^{\mathrm{c}}$ School of Physical Science and Technology, ShanghaiTech University, 100 Haike Road, Shanghai 201210, China

${ }^{\dagger}$ J.-C. X. and Z.-J. W. contributed equally to this work.

E-mail: qinggu@sioc.ac.cn; slyou@ sioc.ac.cn
}

Table of Contents page 


\section{Copies of NMR spectra}

${ }^{1} \mathrm{H}$ NMR and ${ }^{13} \mathrm{C}$ NMR spectrum of $\mathbf{3 a}$
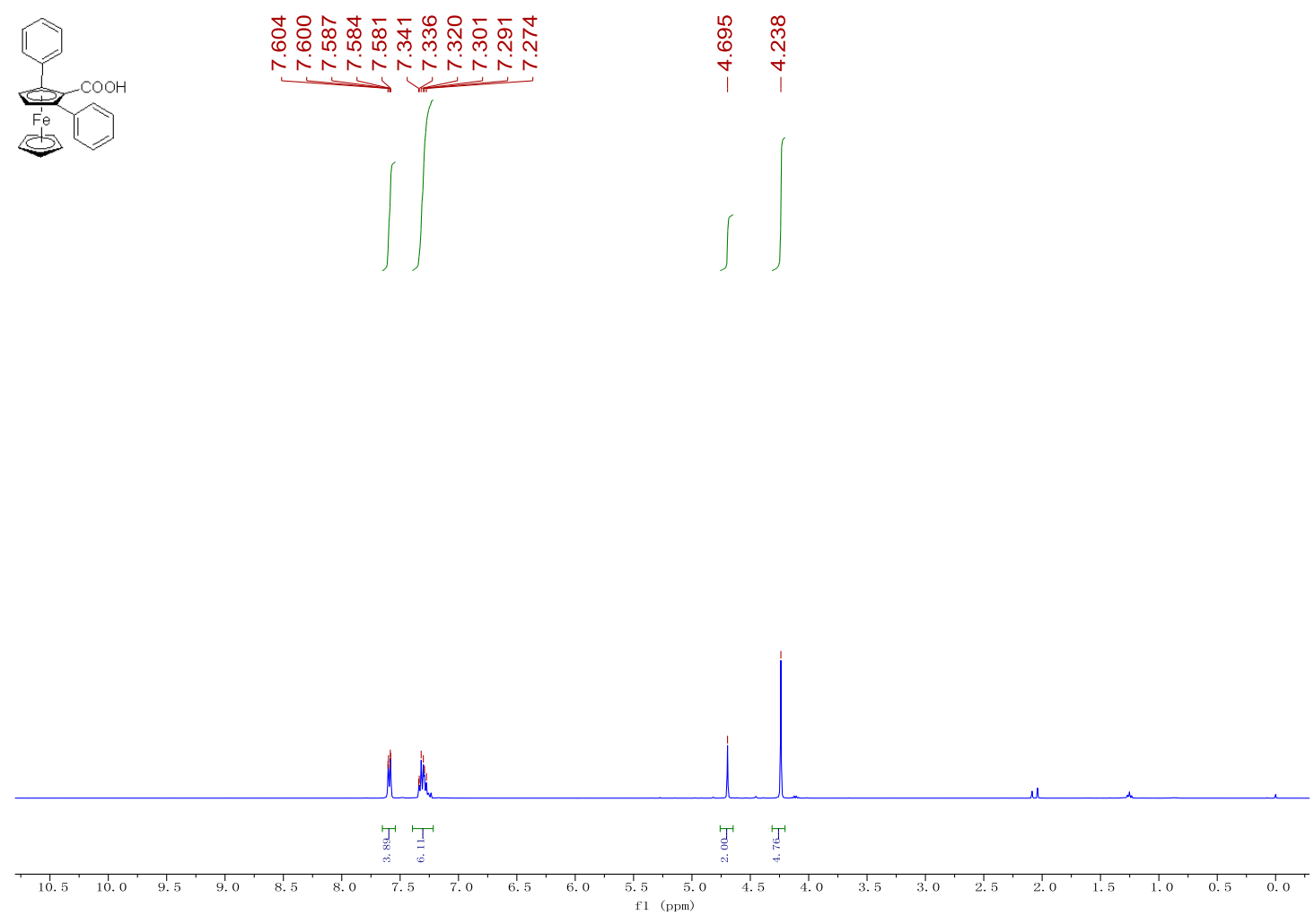

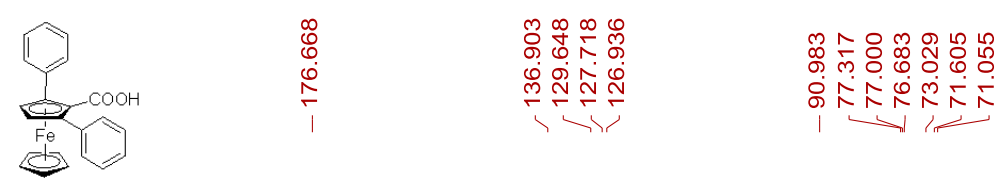

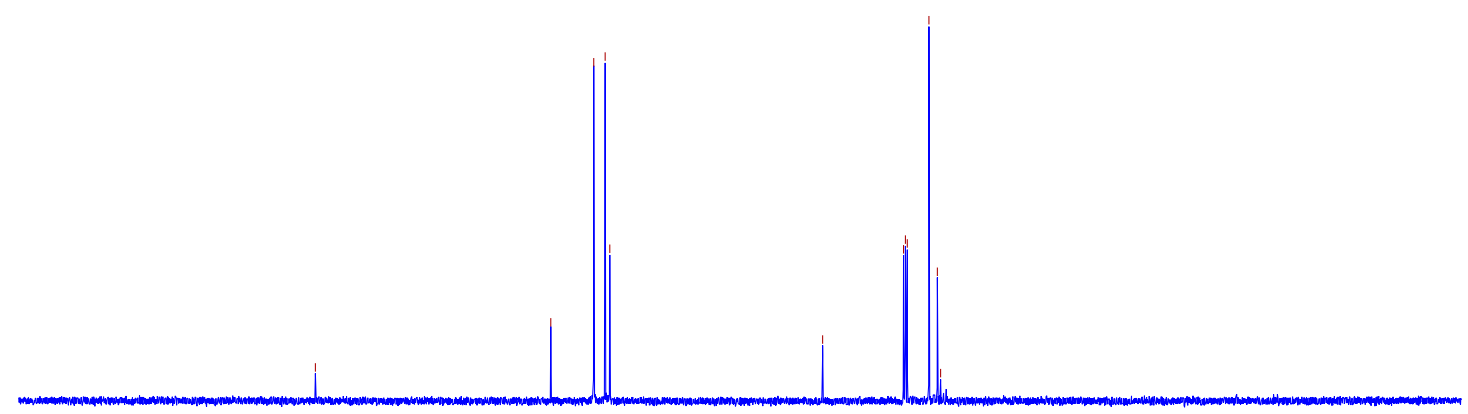

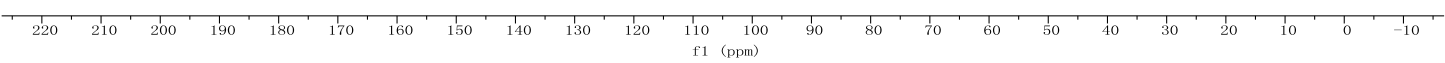


${ }^{1} \mathrm{H}$ NMR and ${ }^{13} \mathrm{C}$ NMR spectrum of $\mathbf{3 b}$
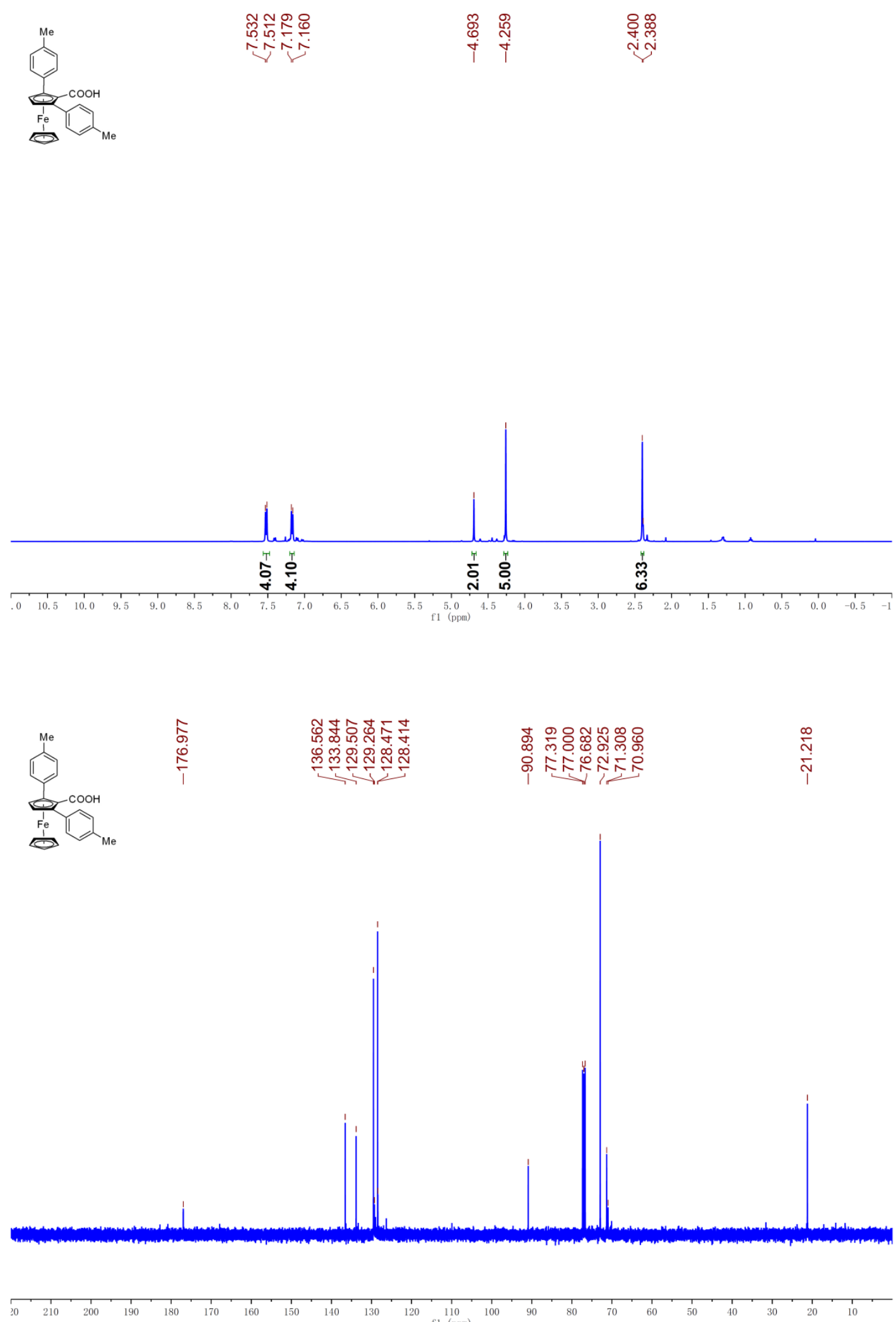
${ }^{1} \mathrm{H}$ NMR and ${ }^{13} \mathrm{C}$ NMR spectrum of $\mathbf{3 c}$
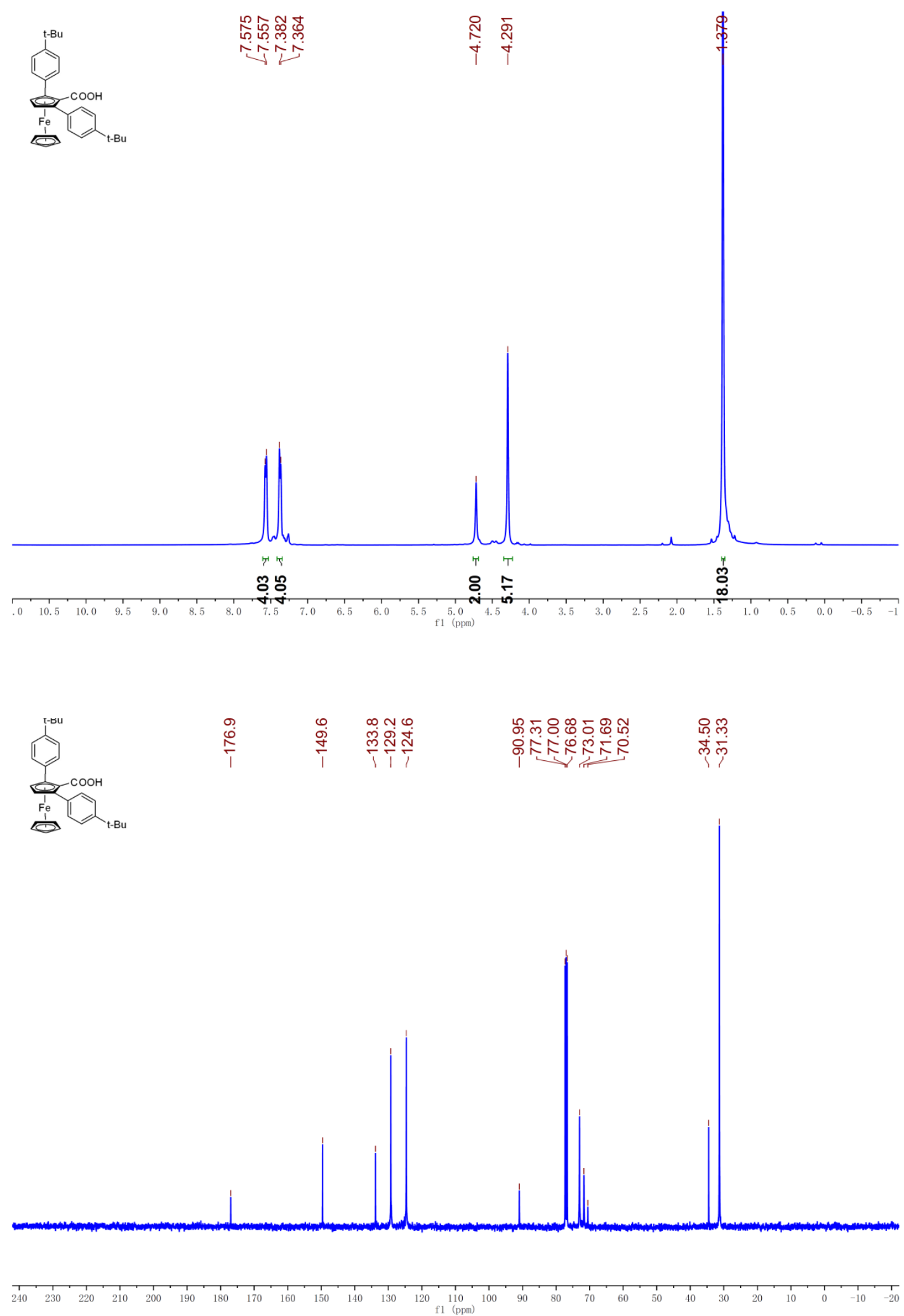
${ }^{1} \mathrm{H}$ NMR and ${ }^{13} \mathrm{C}$ NMR spectrum of $\mathbf{3 d}$

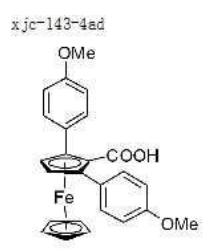

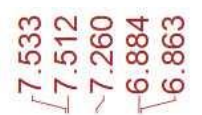

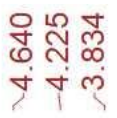

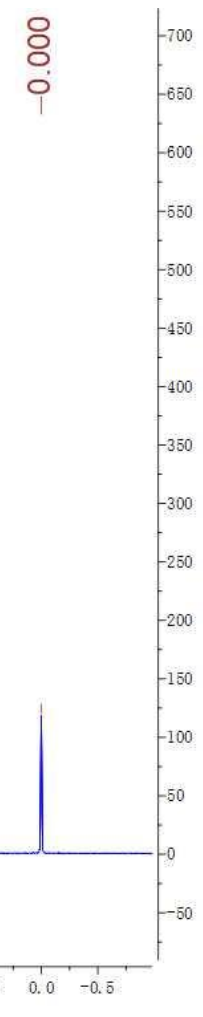

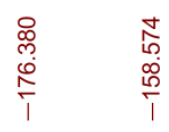

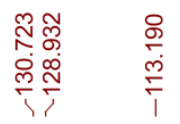

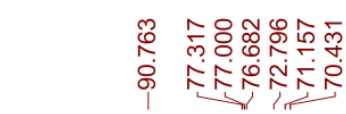

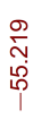

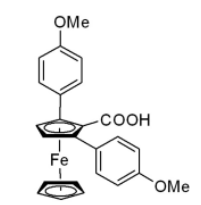

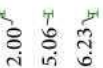

$-50$

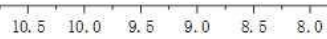
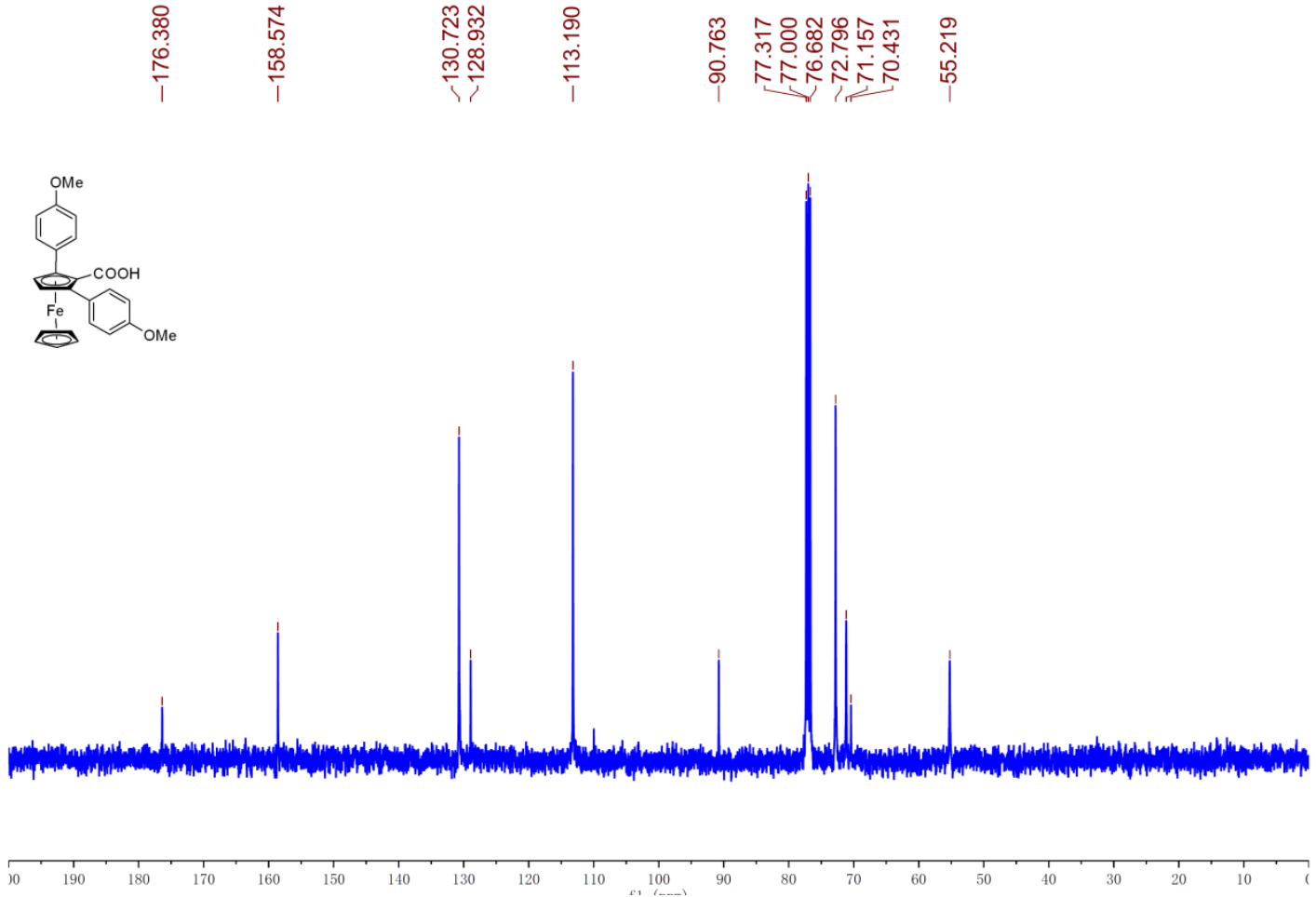

SF 

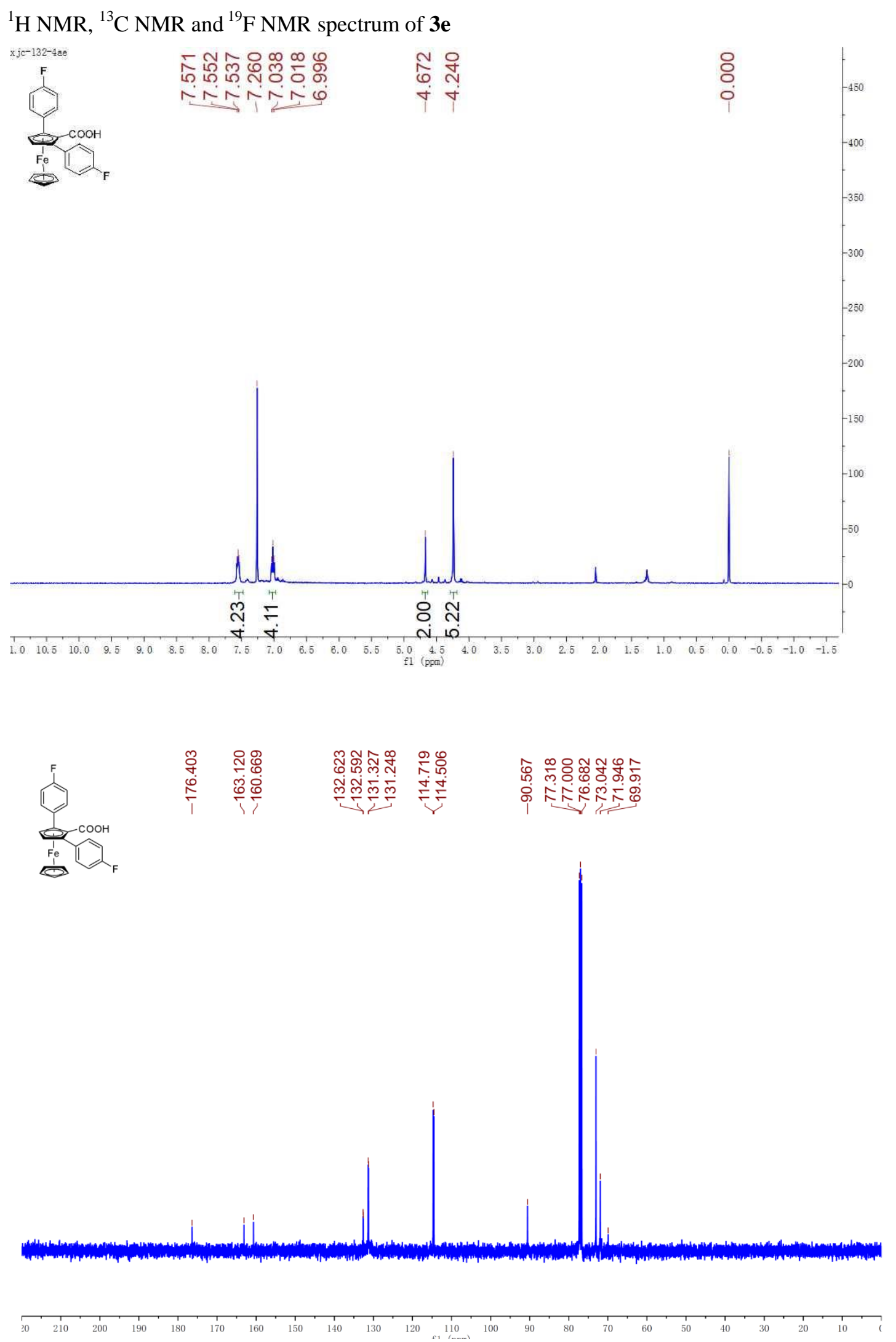

S6 

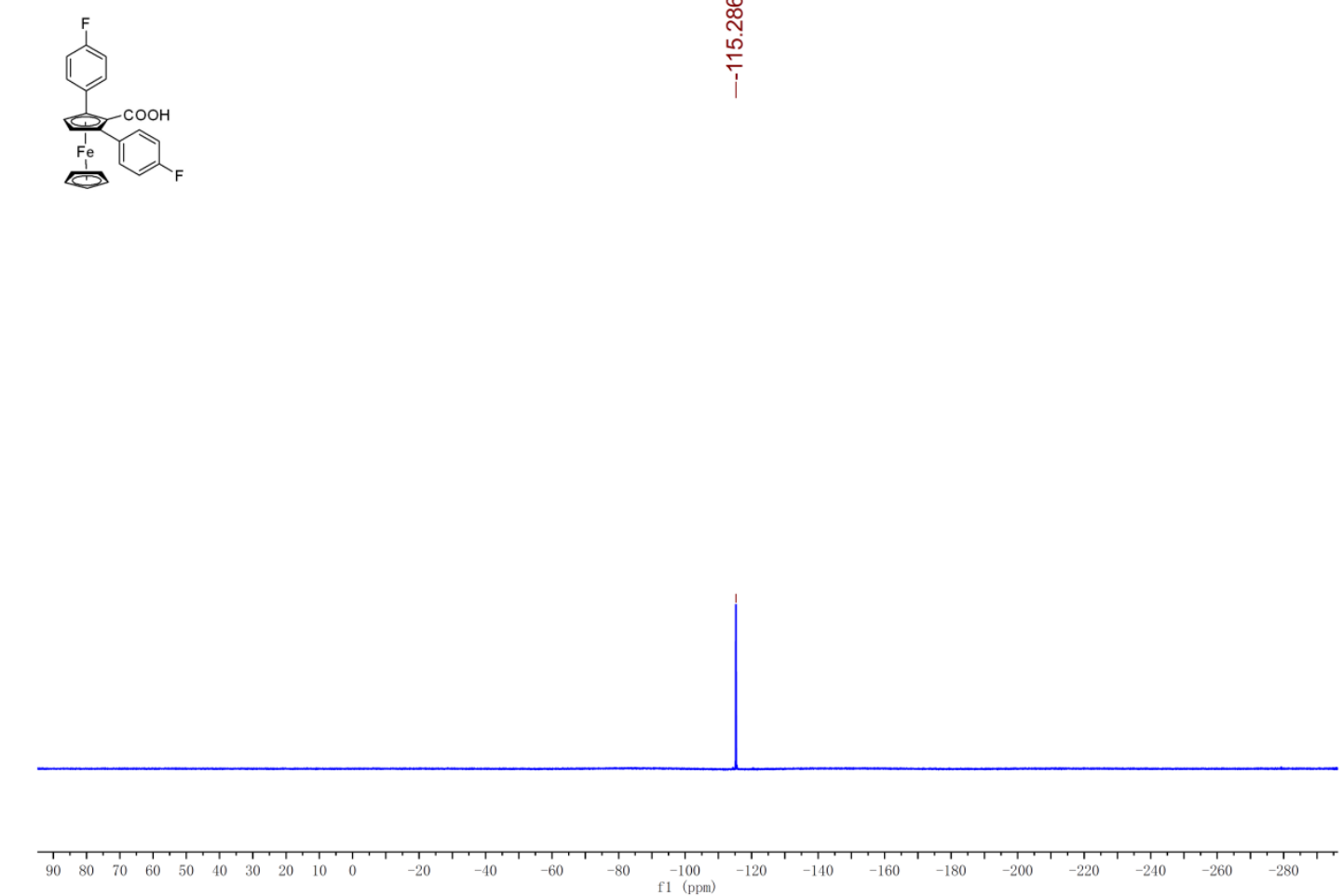

${ }^{1} \mathrm{H}$ NMR and ${ }^{13} \mathrm{C}$ NMR spectrum of $\mathbf{3 f}$

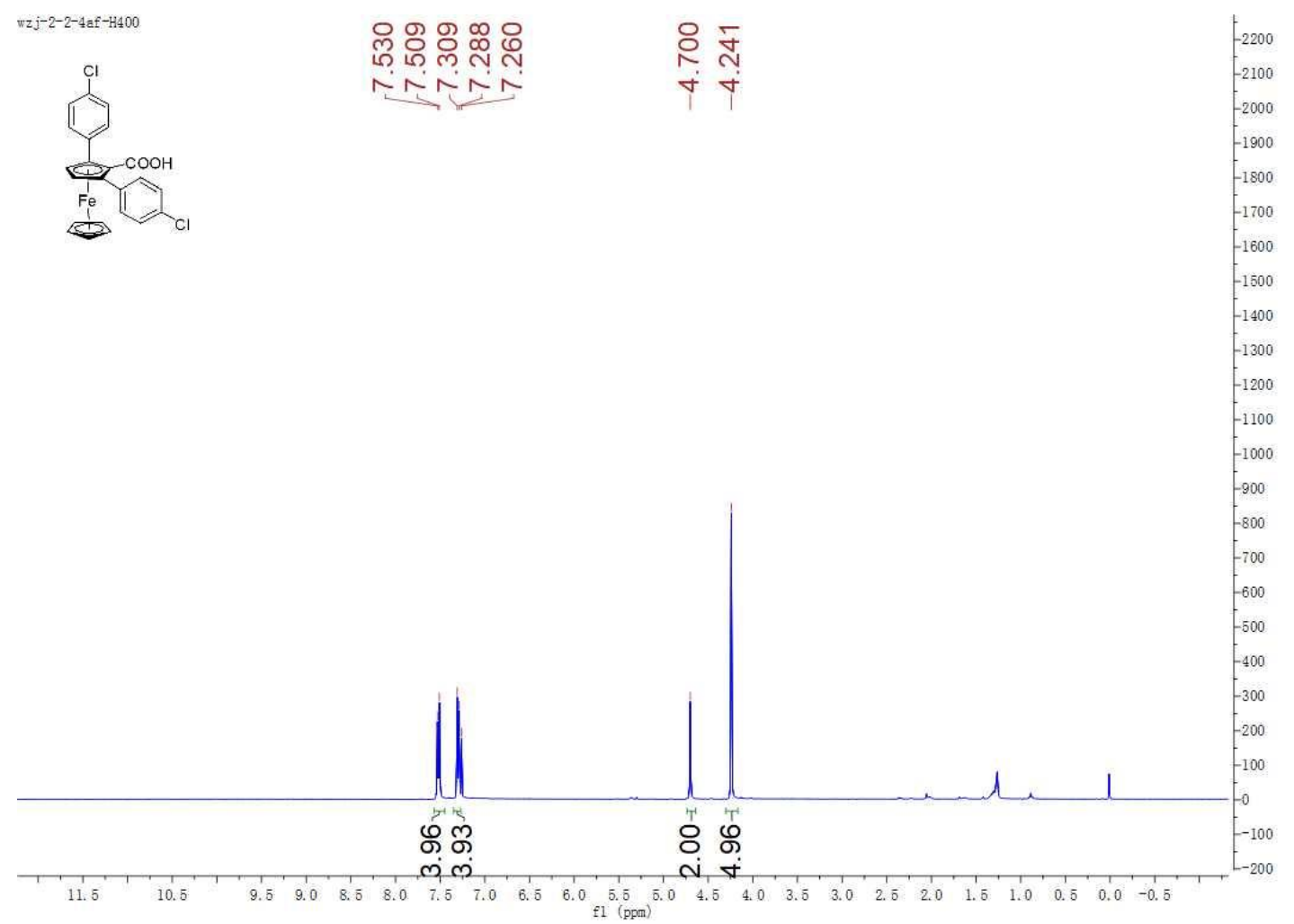




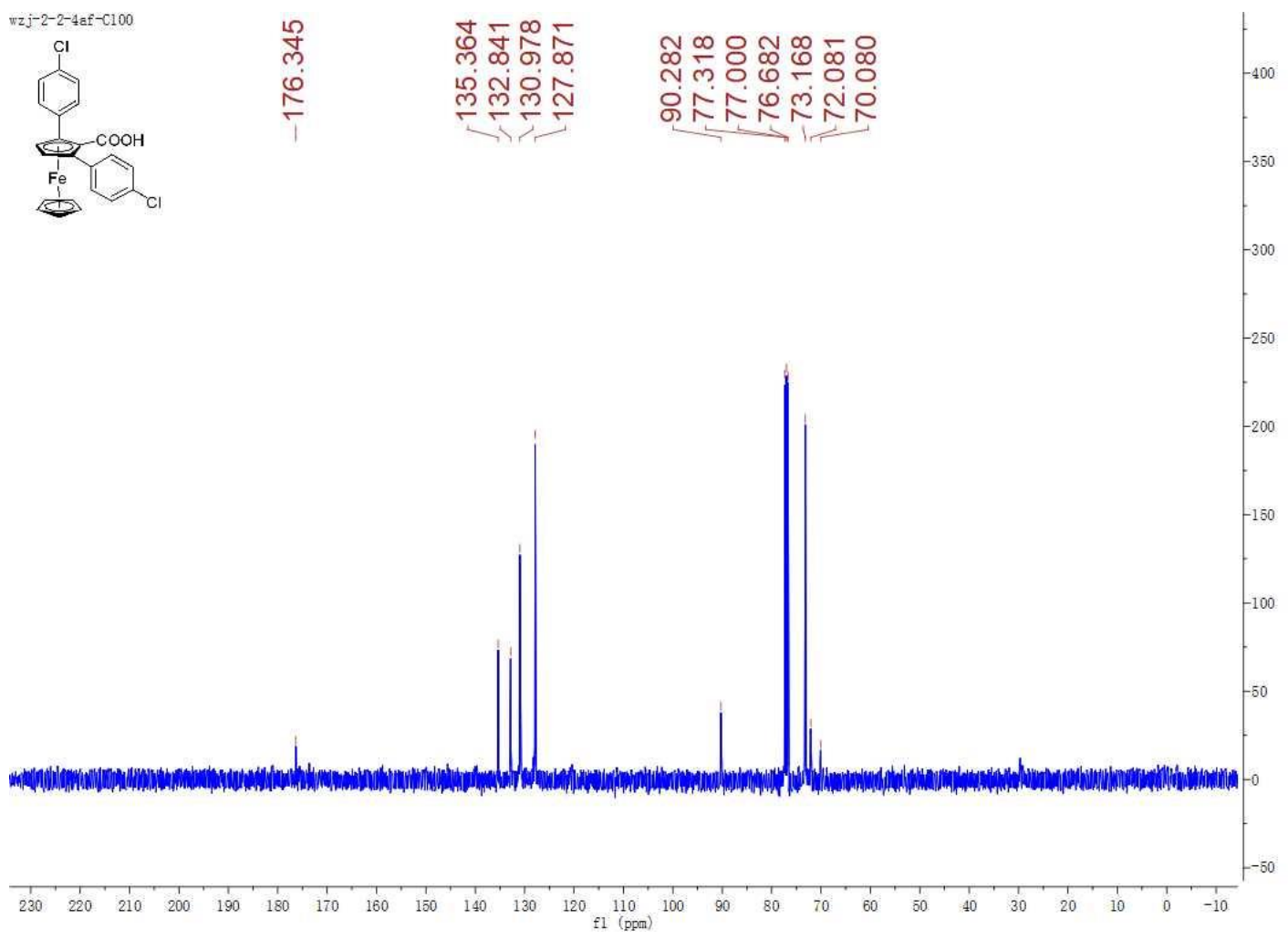

${ }^{1} \mathrm{H}$ NMR and ${ }^{13} \mathrm{C}$ NMR spectrum of $\mathbf{3 g}$

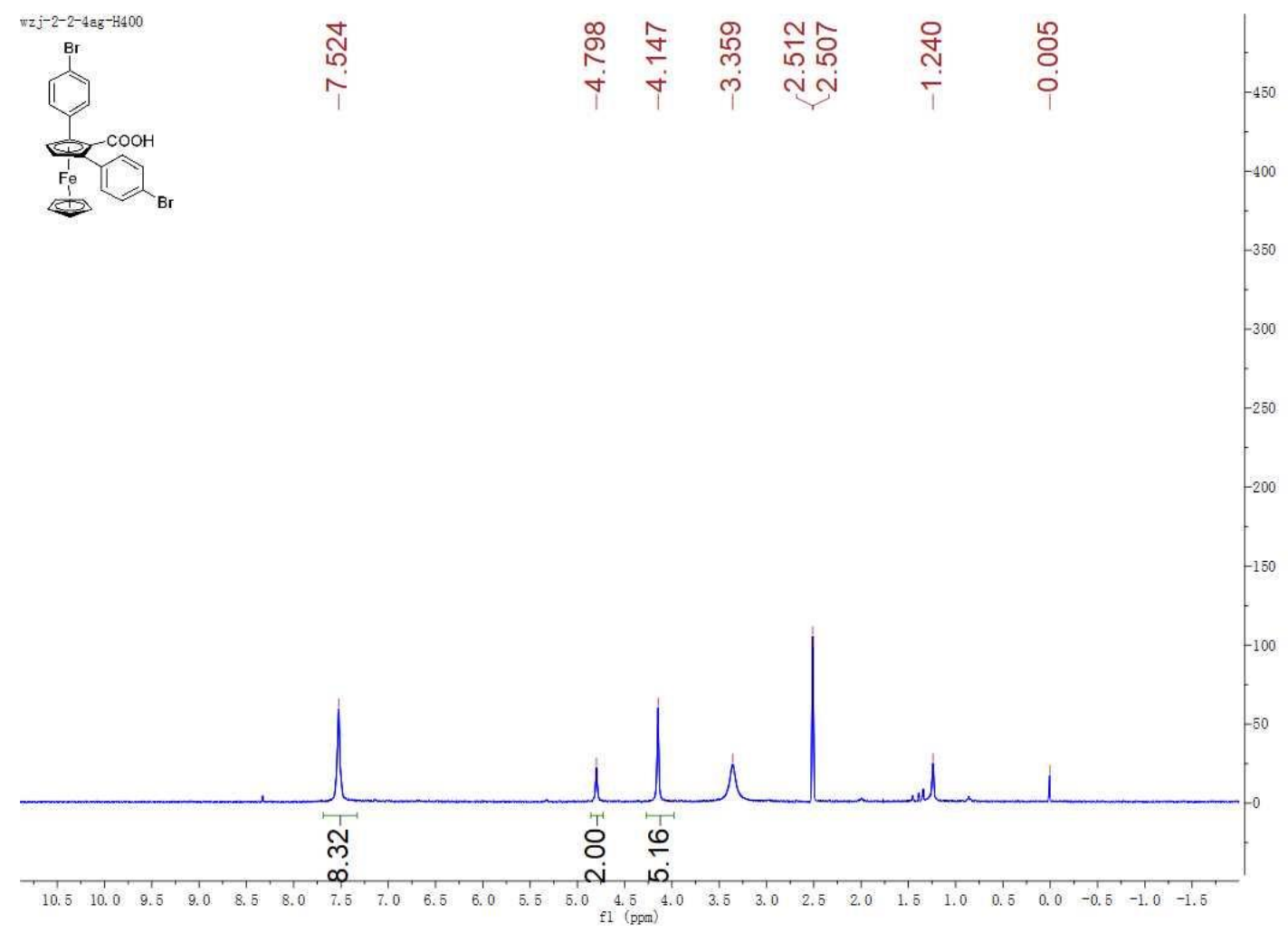

So 


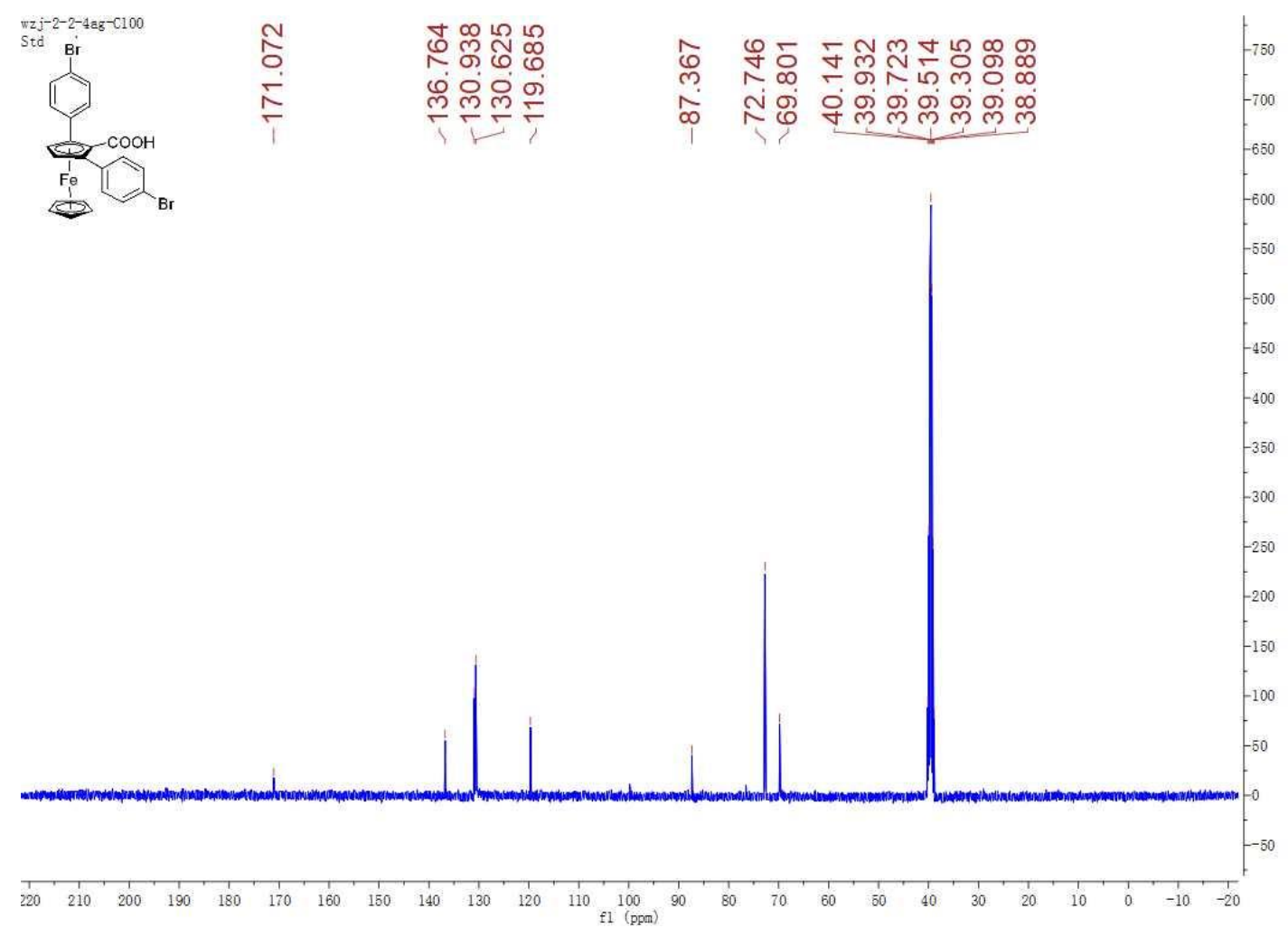

${ }^{1} \mathrm{H}$ NMR, ${ }^{13} \mathrm{C}$ NMR and ${ }^{19} \mathrm{~F}$ NMR spectrum of $\mathbf{3 h}$
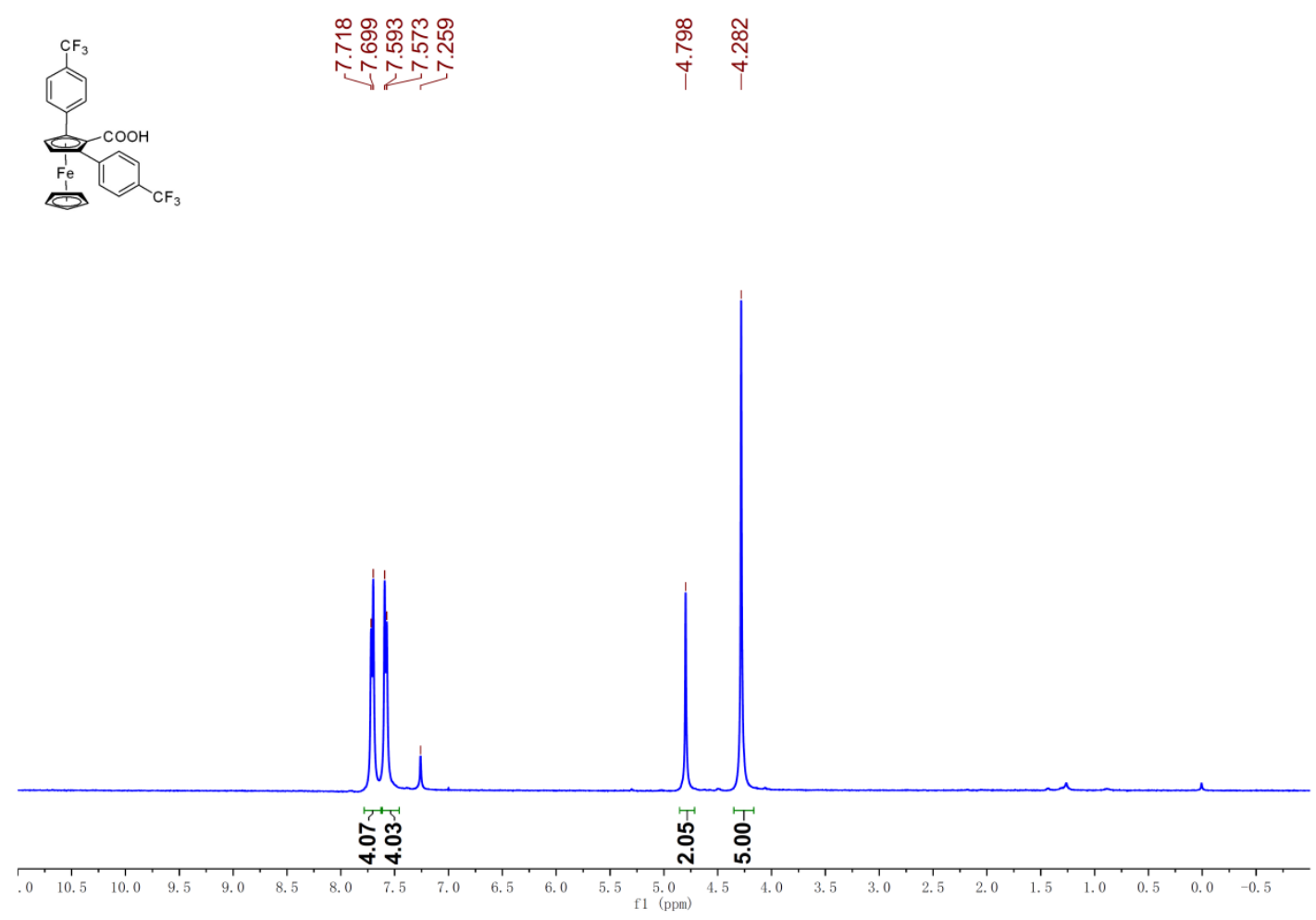

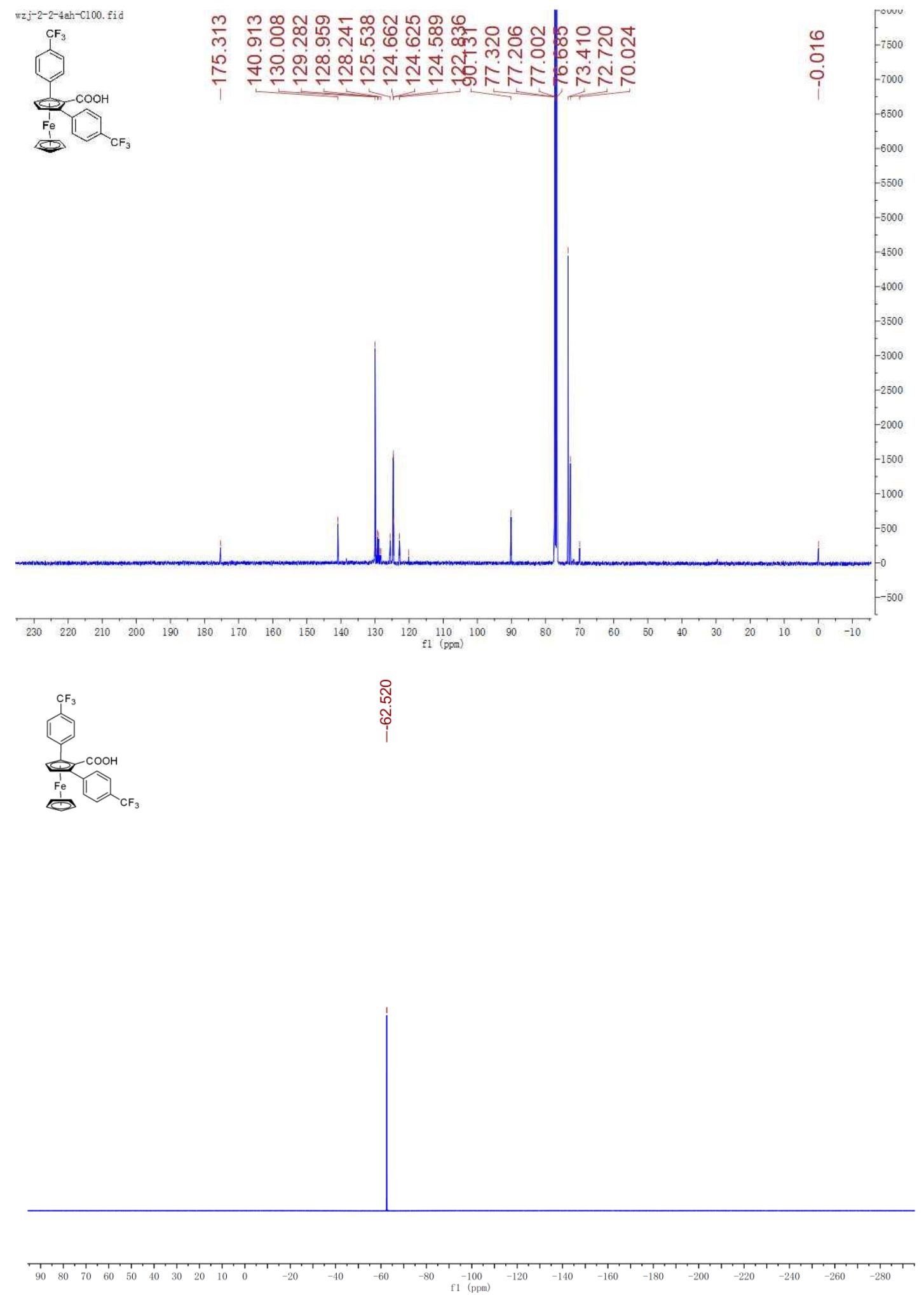

$\mathrm{S} 10$ 
${ }^{1} \mathrm{H}$ NMR and ${ }^{13} \mathrm{C}$ NMR spectrum of $\mathbf{3 i}$
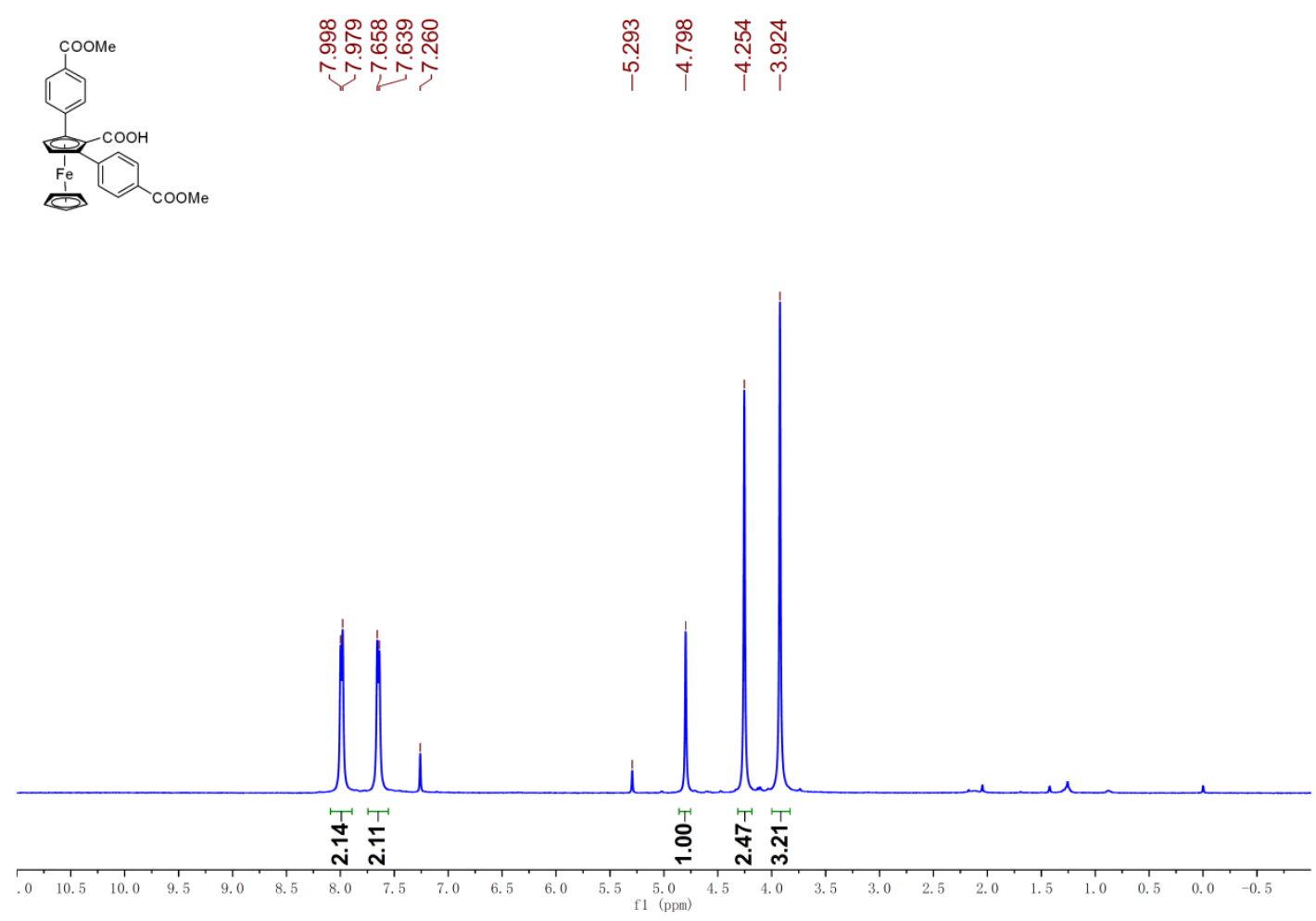

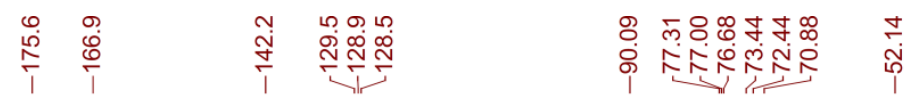

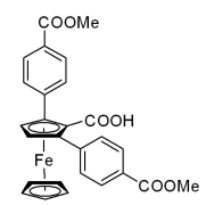


${ }^{1} \mathrm{H}$ NMR and ${ }^{13} \mathrm{C}$ NMR spectrum of $\mathbf{3 j}$
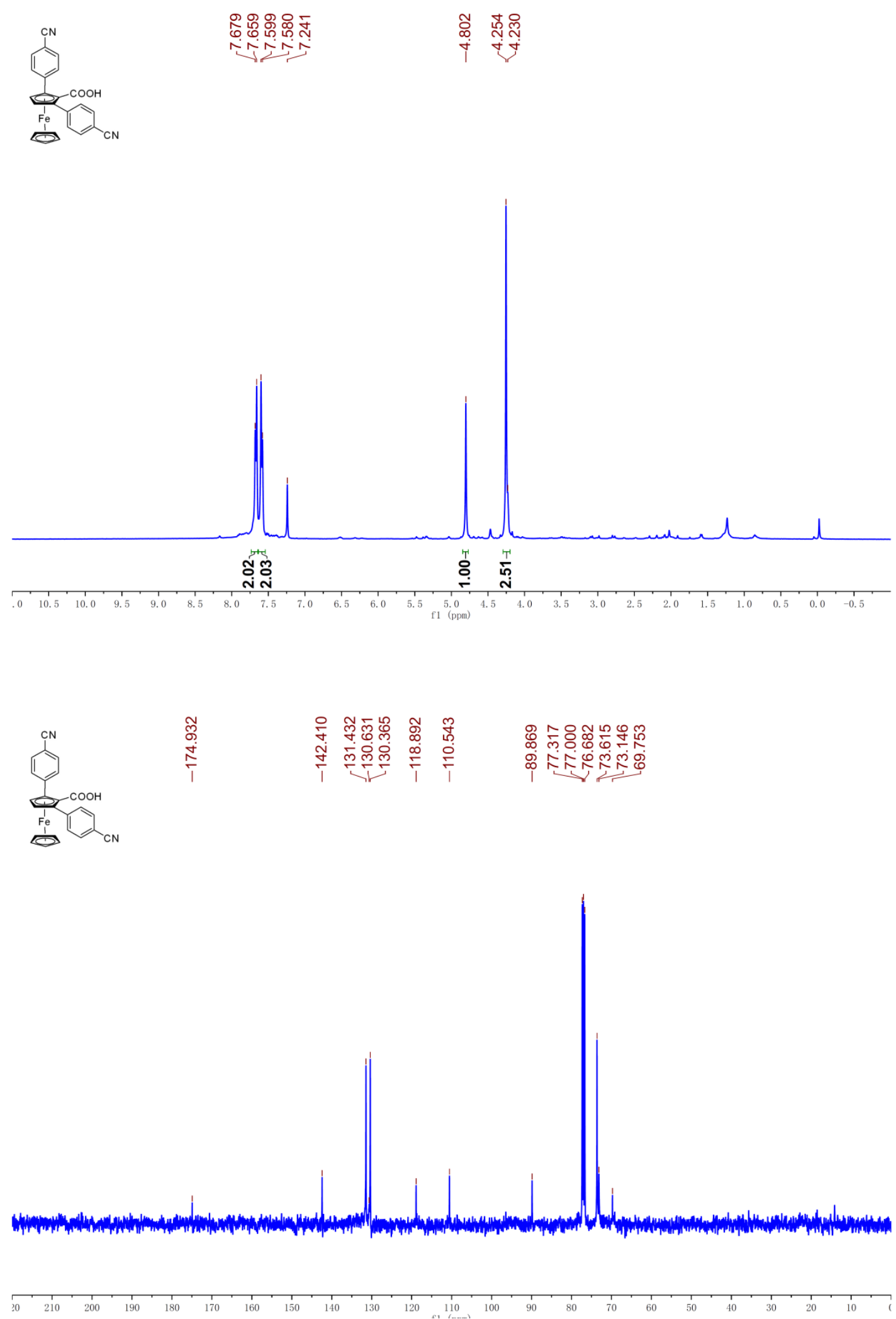
${ }^{1} \mathrm{H}$ NMR and ${ }^{13} \mathrm{C}$ NMR spectrum of $\mathbf{3 k}$
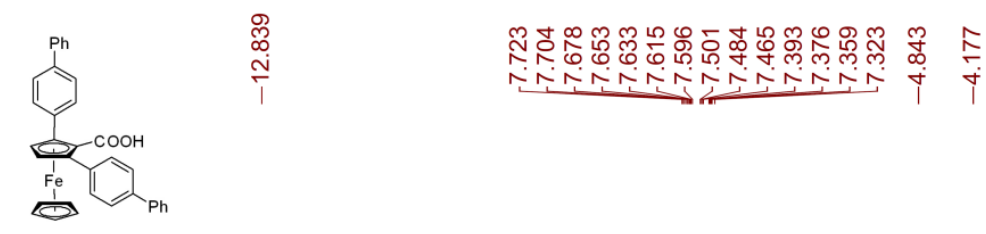

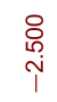
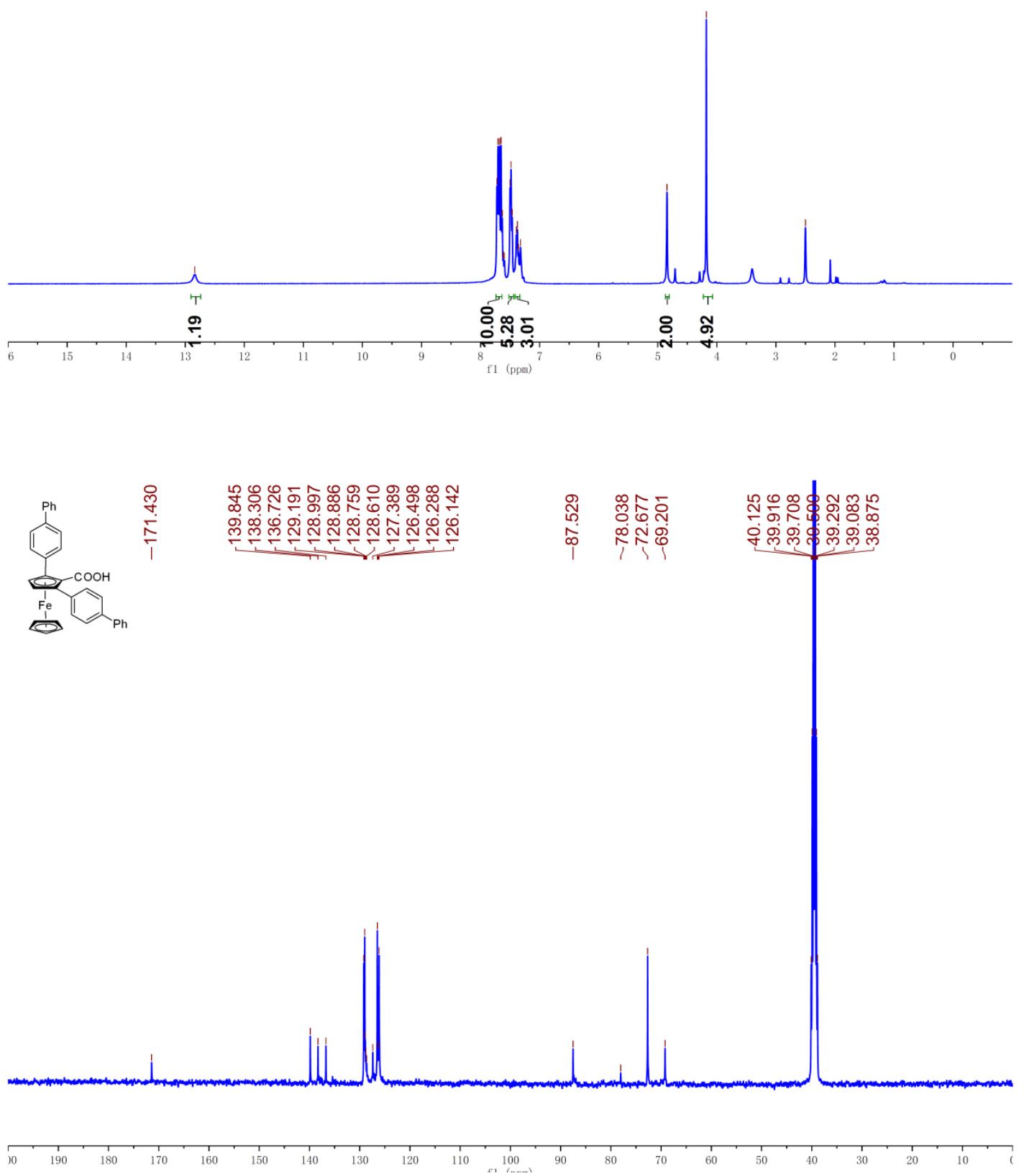

S13 
${ }^{1} \mathrm{H}$ NMR and ${ }^{13} \mathrm{C}$ NMR spectrum of $\mathbf{3 l}$
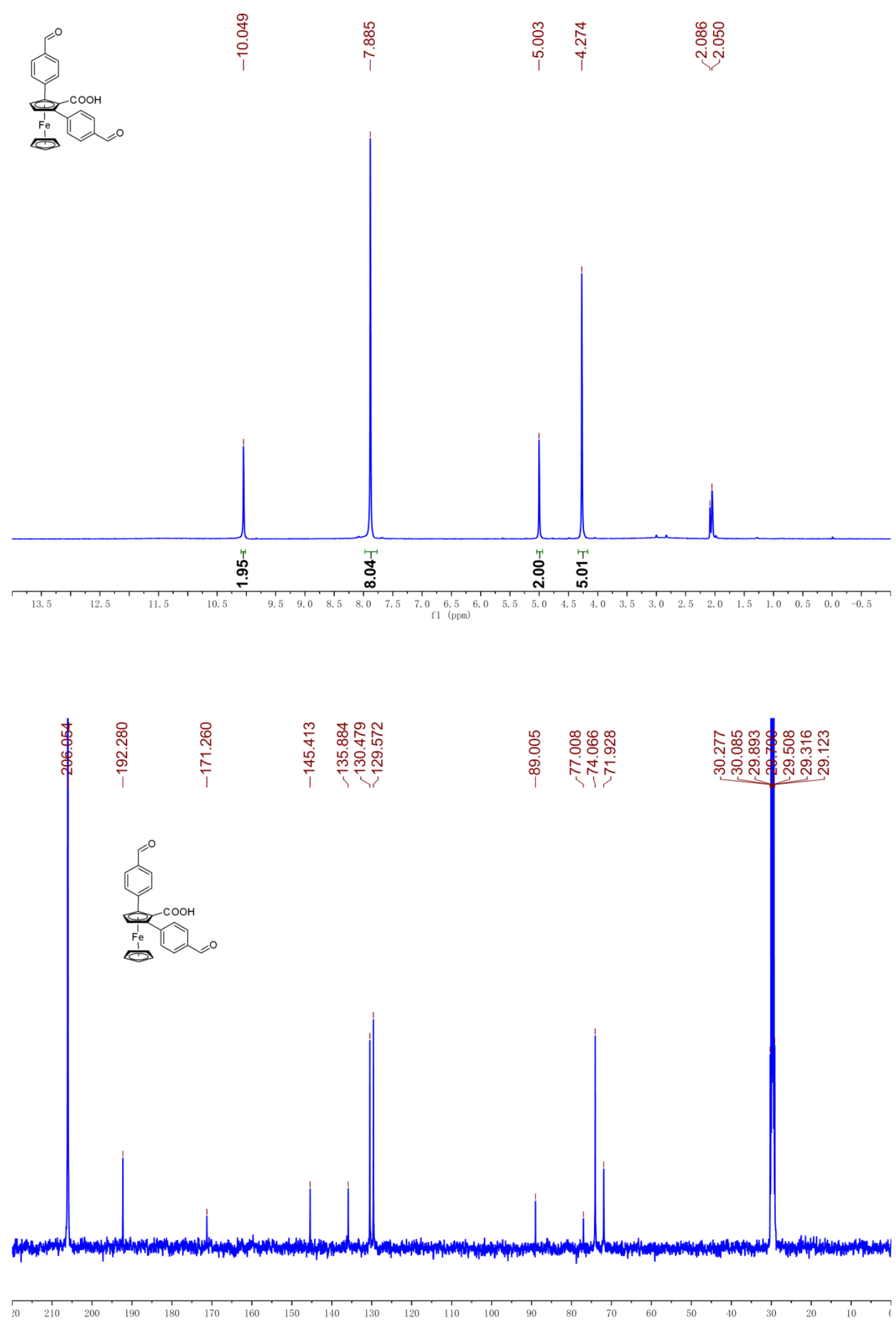
${ }^{1} \mathrm{H}$ NMR and ${ }^{13} \mathrm{C}$ NMR spectrum of $\mathbf{3 m}$
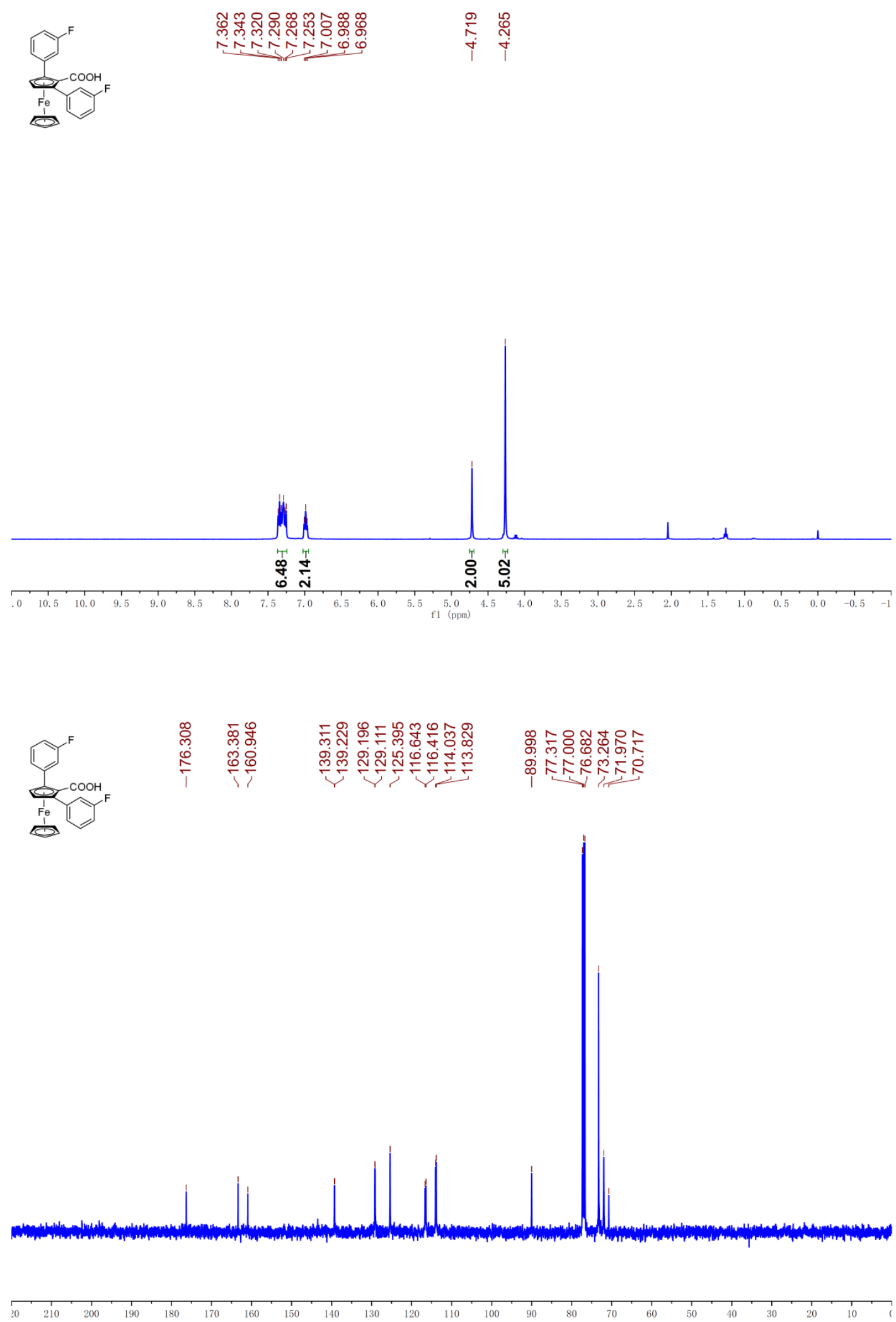

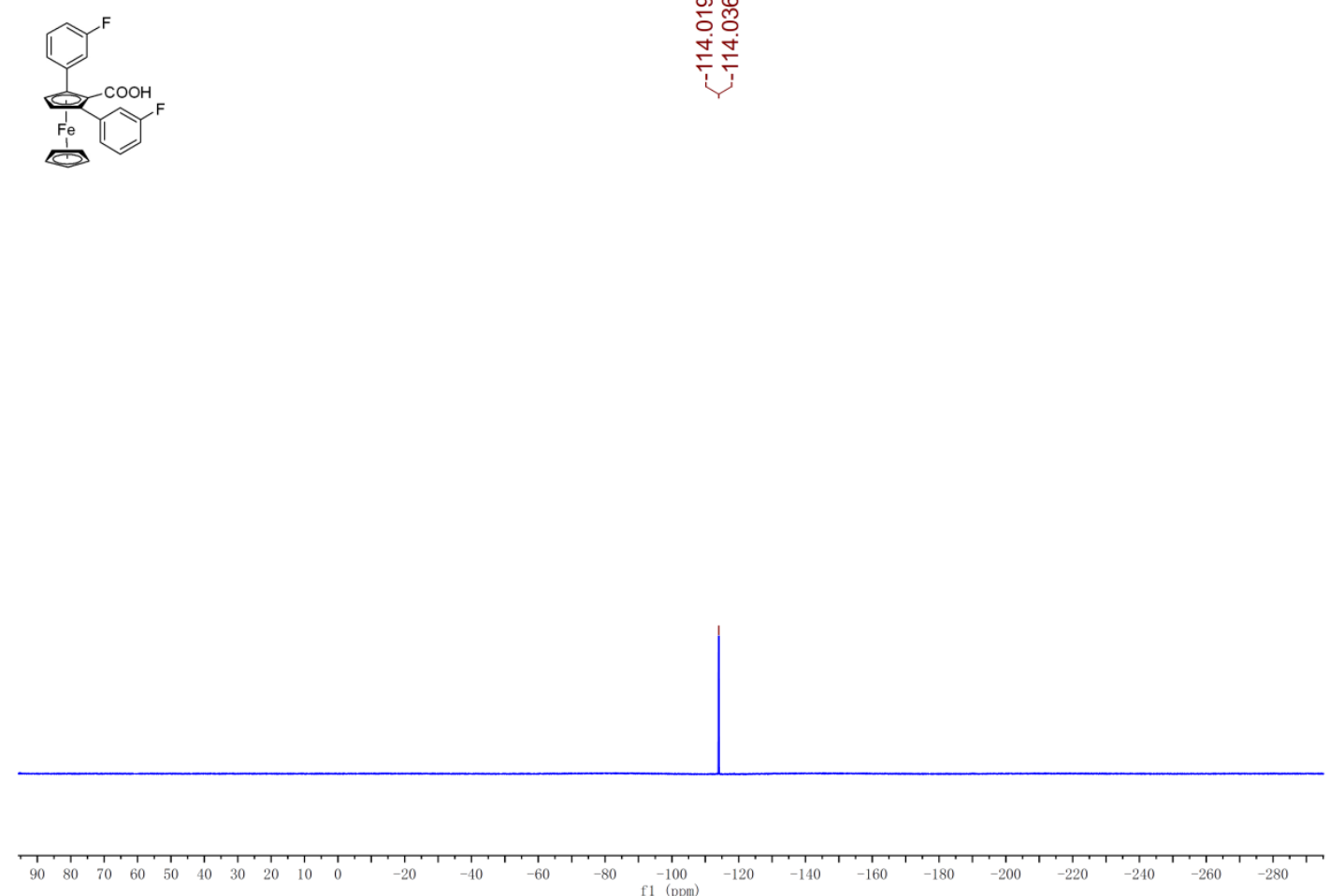

${ }^{1} \mathrm{H}$ NMR and ${ }^{13} \mathrm{C}$ NMR spectrum of $\mathbf{3 n}$
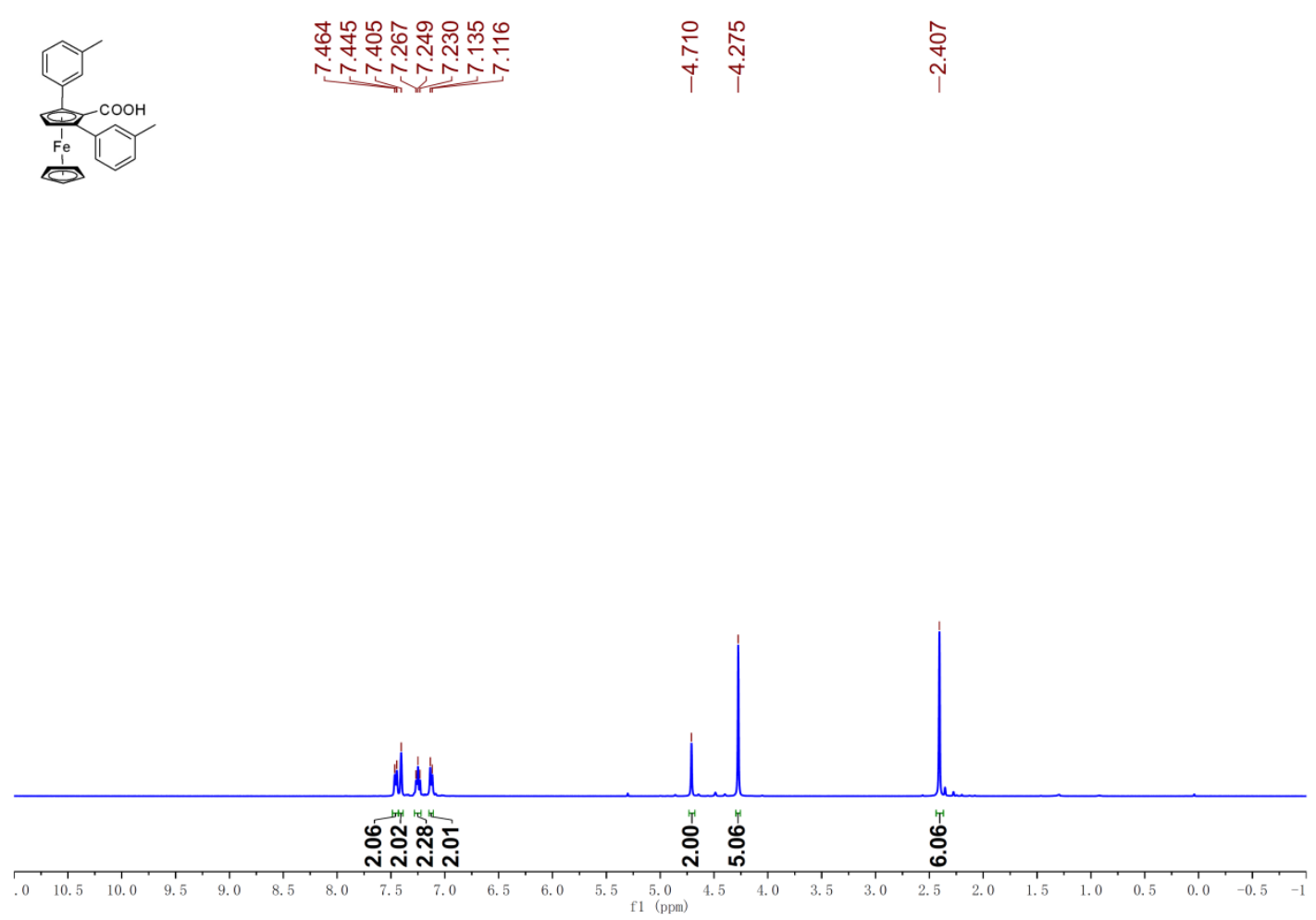


$\begin{array}{llll}1 & 0 & 0 \\ 0 & 0 & 0\end{array}$

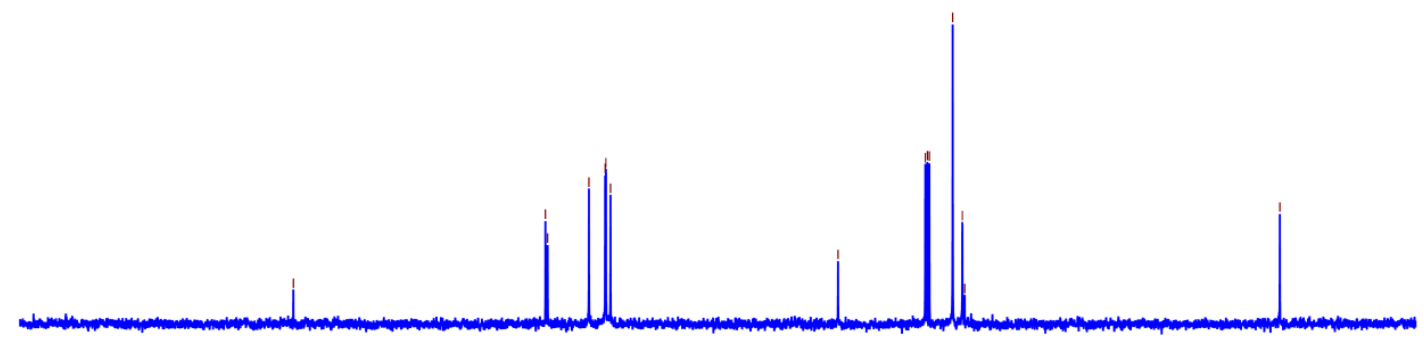

${ }^{1} \mathrm{H}$ NMR and ${ }^{13} \mathrm{C}$ NMR spectrum of $\mathbf{3 o}$

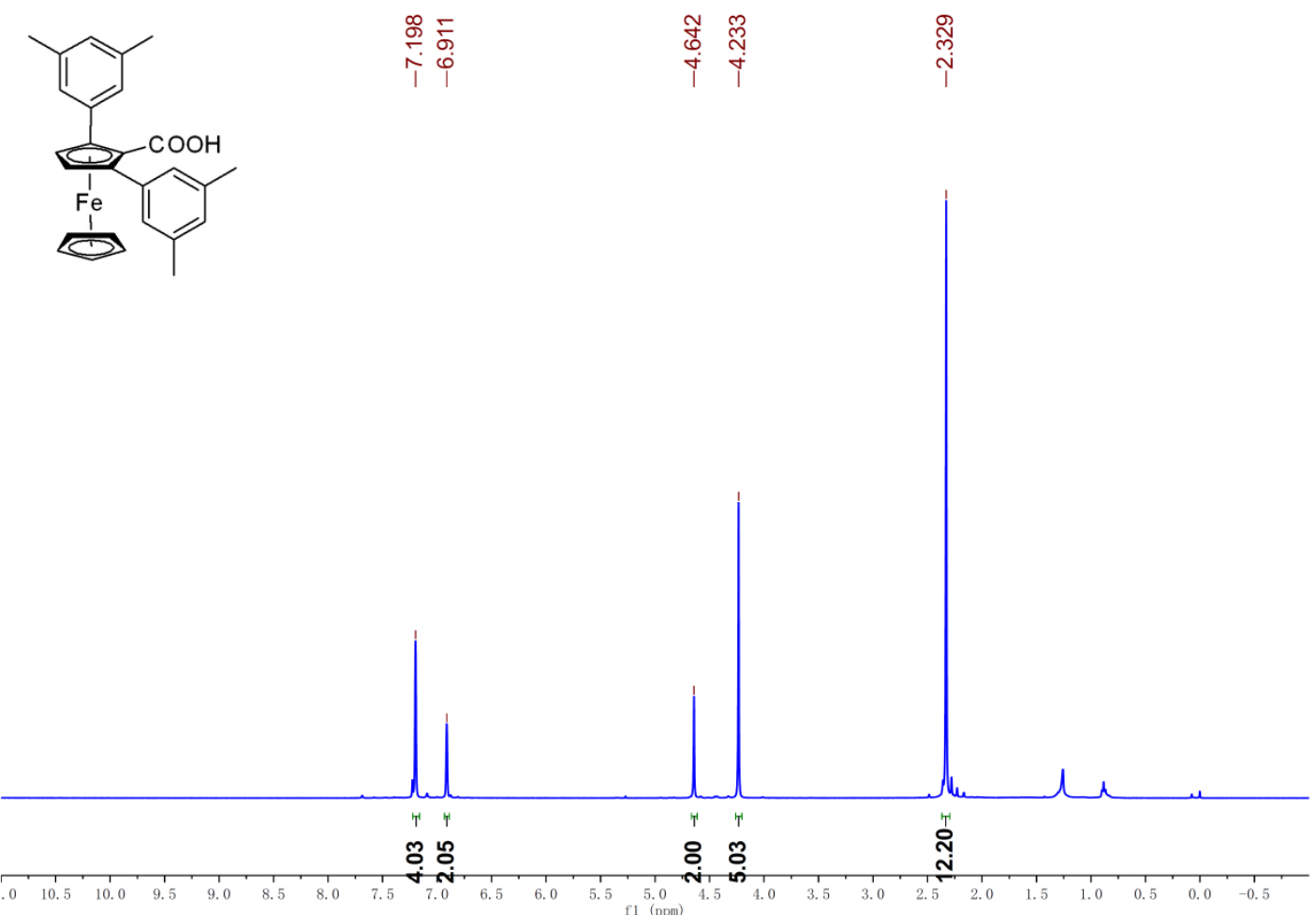



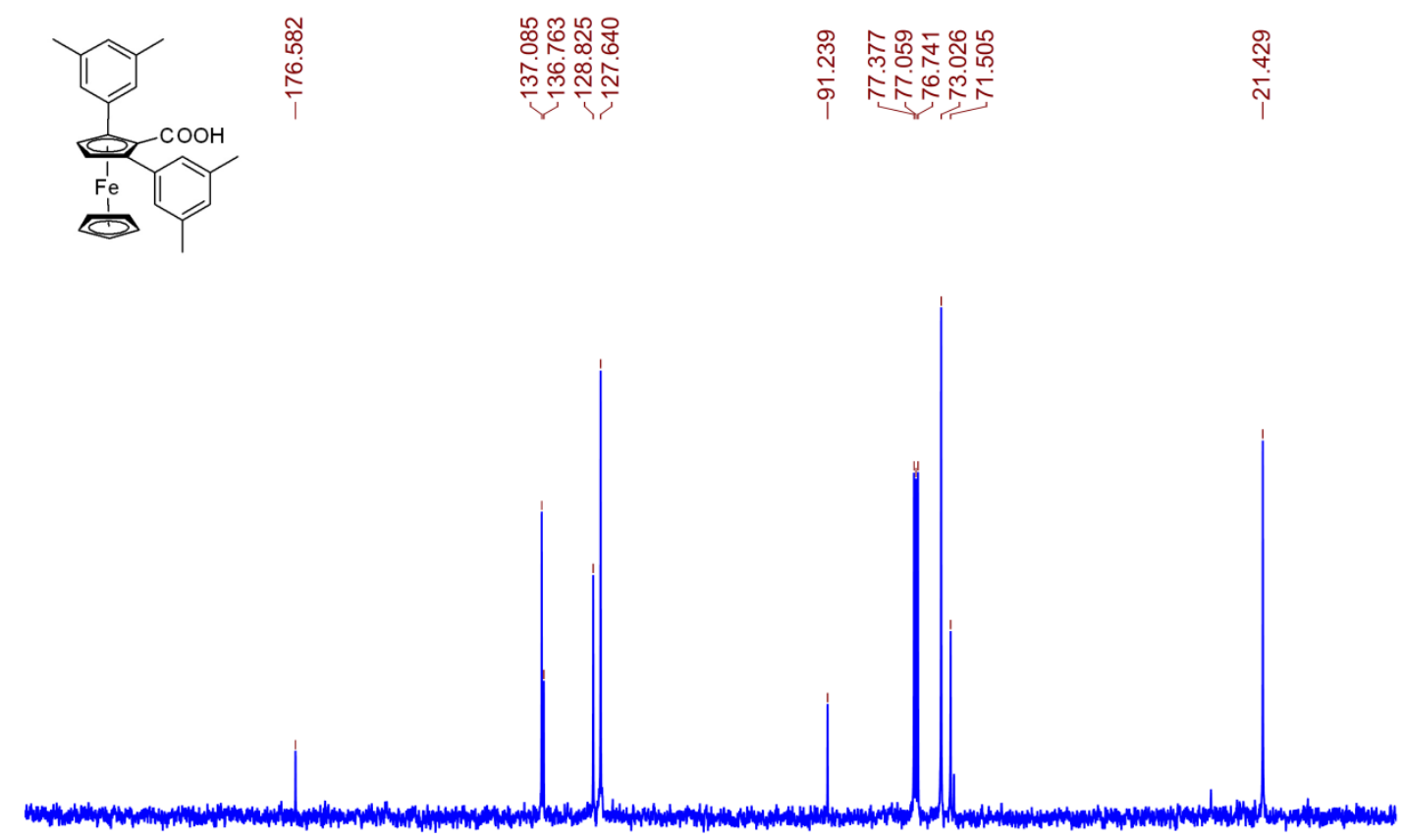

${ }^{1} \mathrm{H}$ NMR and ${ }^{13} \mathrm{C}$ NMR spectrum of $\mathbf{6}$

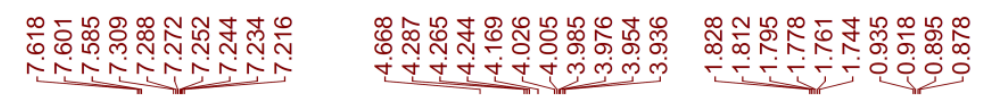

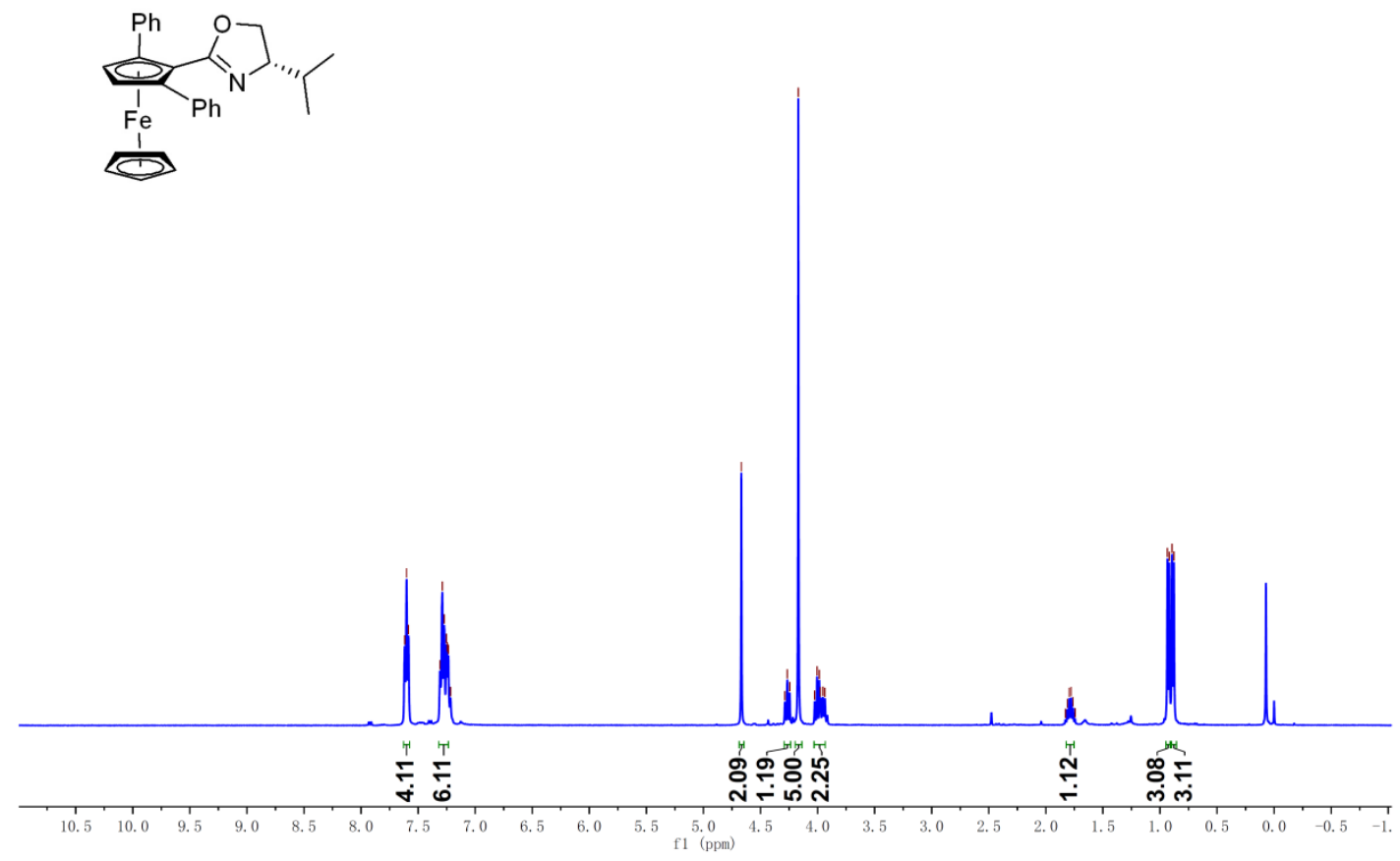




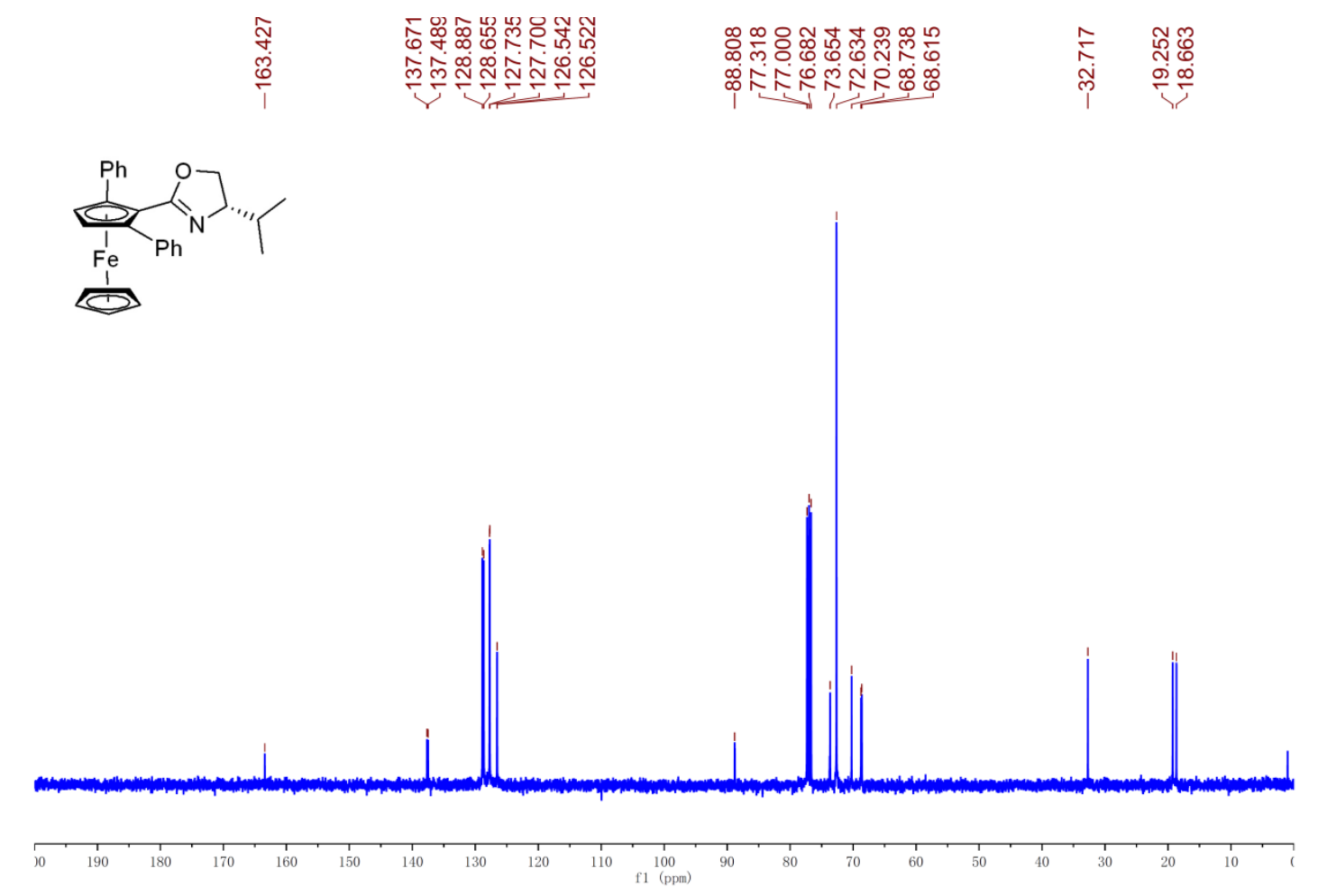

${ }^{1} \mathrm{H}$ NMR and ${ }^{13} \mathrm{C}$ NMR spectrum of 7

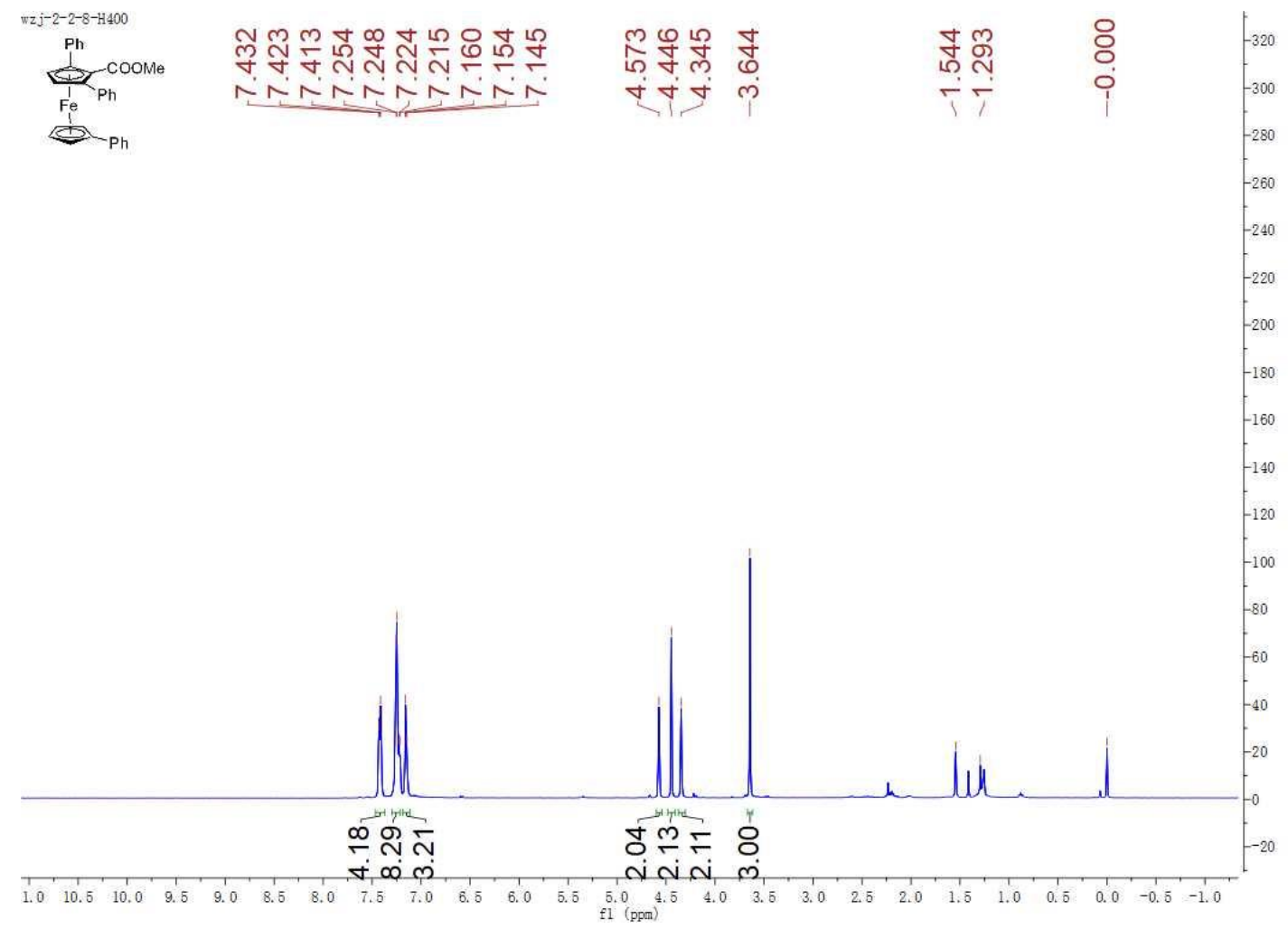




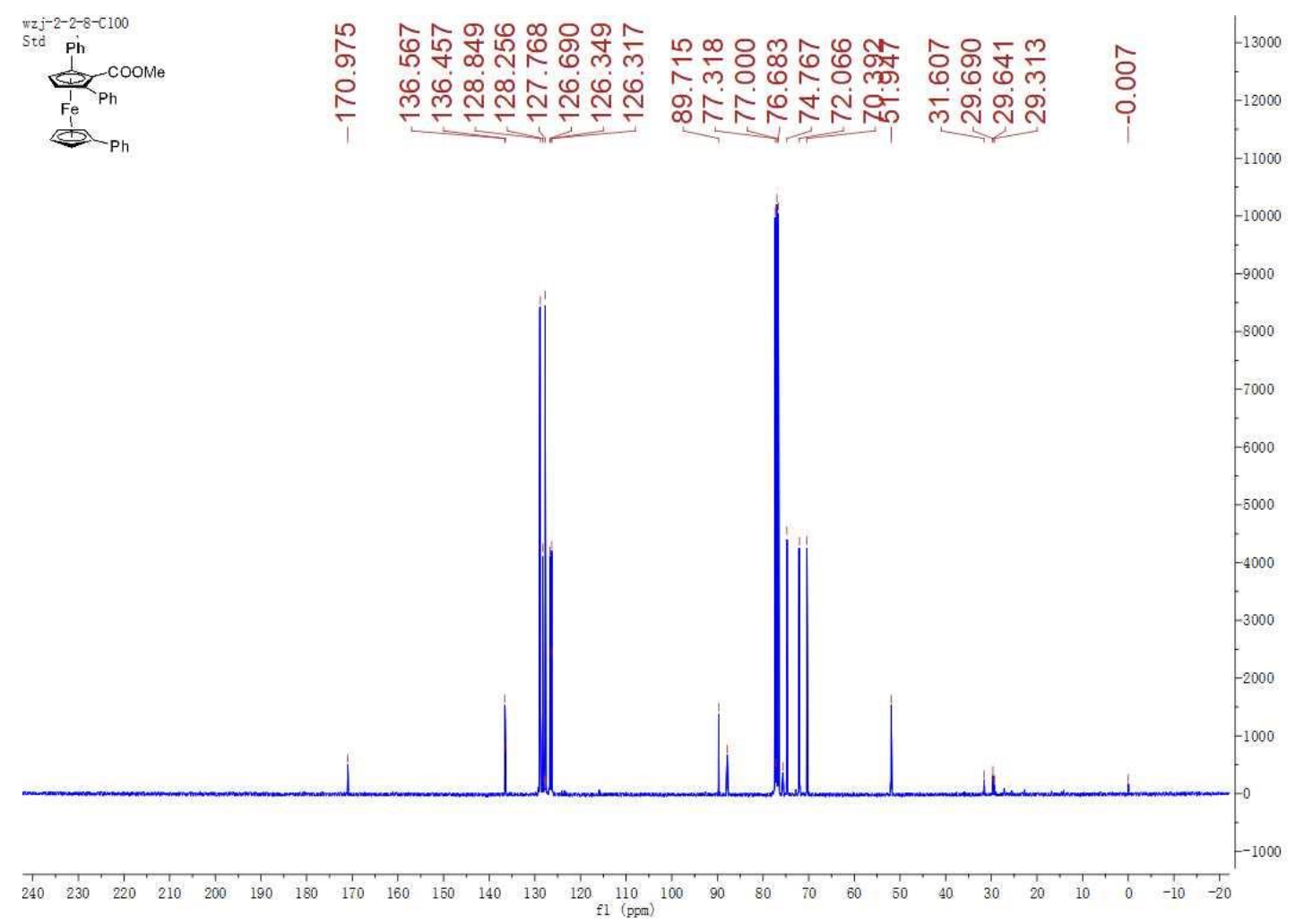

${ }^{1}$ H NMR and ${ }^{13}$ C NMR spectrum of 8

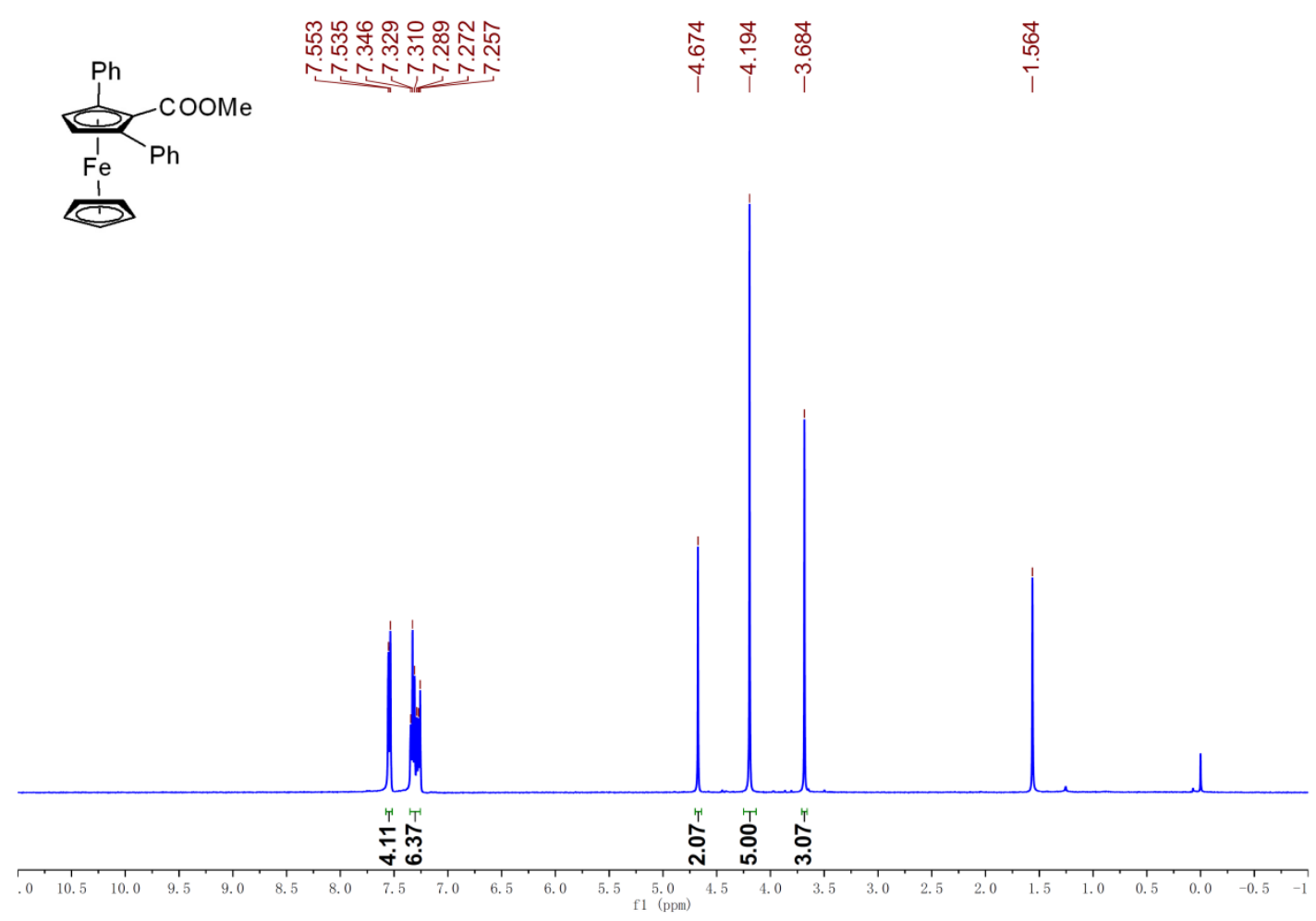




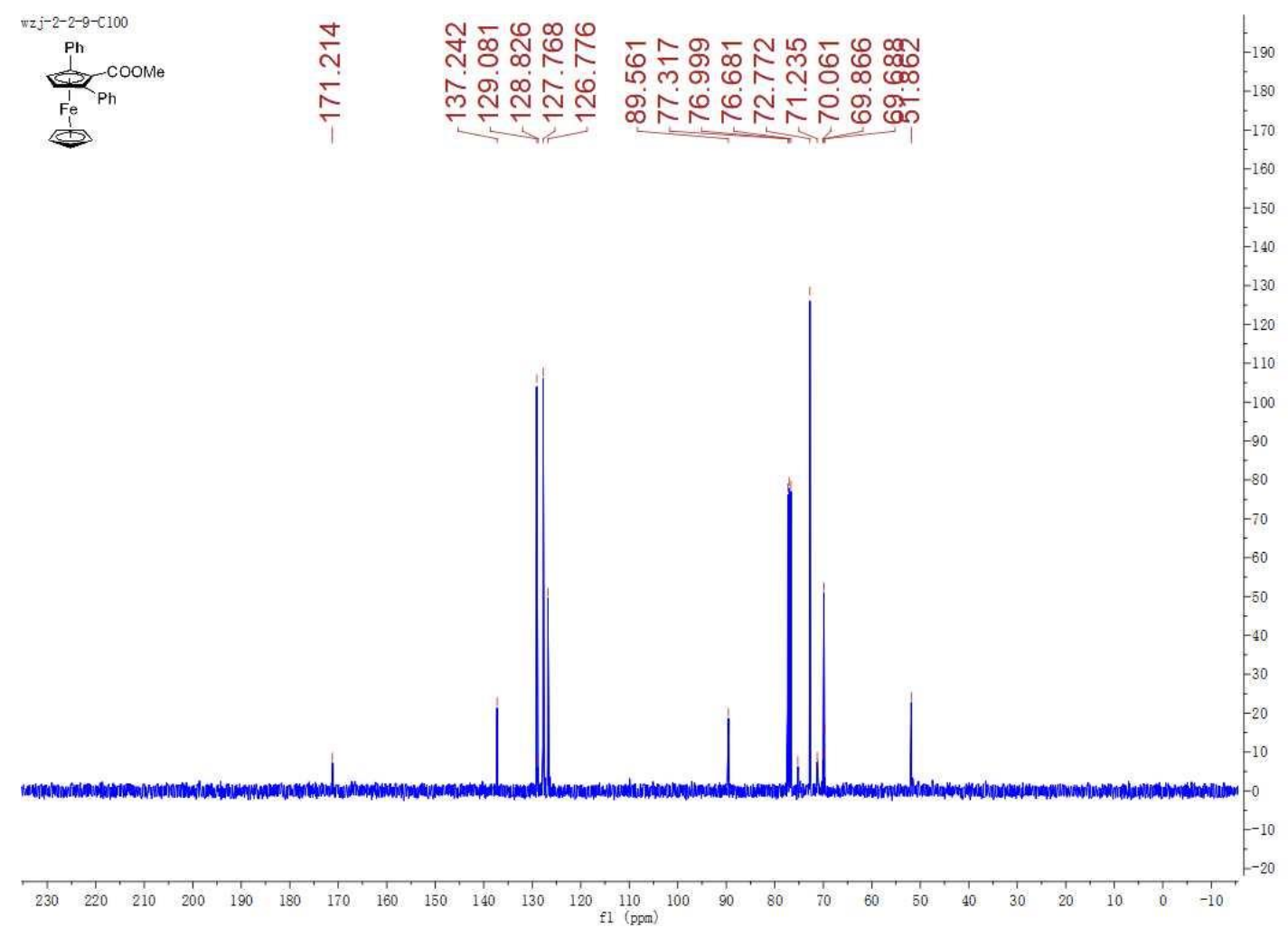

